Following the Molecular Mechanism of Decarbonylation of Unsaturated Cyclic Ketones Using Bonding Evolution Theory Coupled with NCI Analysis Peer-reviewed author version

Zahedi, Ehsan; Shaabani, Samaneh \& SHIROUDI, Abolfazl (2017) Following the Molecular Mechanism of Decarbonylation of Unsaturated Cyclic Ketones Using Bonding Evolution Theory Coupled with NCI Analysis. In: JOURNAL OF PHYSICAL CHEMISTRY A, 121(44), p. 8504-8517.

DOI: $10.1021 /$ acs.jpca.7b08503

Handle: http://hdl.handle.net/1942/25156 


\title{
Following the Molecular Mechanism of Decarbonylation of Unsaturated Cyclic Ketones Using Bonding Evolution Theory Coupled with NCI Analysis
}

\author{
Ehsan Zahedi ${ }^{a}{ }^{\dagger}$, Samaneh Shaabani $^{a}$, Abolfazl Shiroudi ${ }^{b}$ \\ ${ }^{a}$ Chemistry Department, Shahrood Branch, Islamic Azad University, Shahrood, Iran \\ ${ }^{b}$ Center of Molecular and Materials Modelling, Hasselt University, Agoralaan, Gebouw D, B-3590 Diepenbeek, Belgium
}

\begin{abstract}
The synergetic use of bonding evolution theory (BET) and non-covalent interaction (NCI) analysis allows to obtain new insight into the bond breaking/forming processes and electron redistribution along the reaction path to understand the molecular mechanism of a reaction and recognize regions of strong and weak electron pairing. This viewpoint has been considered for cheletropic extrusion of $\mathrm{CO}$ from unsaturated cyclic ketones cyclohepta-3,5-dien-1-one CHD, cyclopent-3-en-1-one CPE and bicyclo[2.2.1]hept-2-en-7-one BCH by using hybrid functional MPWB1K in conjugation with aug-cc-pVTZ basis set. Decarbonylation of CHD, CPE and BCH are non-polar cyclo-elimination reactions which are characterized by the sequence of turning points (TPs) as: CHD: $1-11-\mathrm{C}[\mathrm{CC}] \mathrm{C}^{\dagger} \mathrm{C}^{\dagger} \mathrm{FFF}^{\mathrm{TS}} \mathrm{C}^{\dagger} \mathrm{C}^{\dagger} \mathrm{C}^{\dagger}-0$ : $\mathbf{H T}+\mathrm{CO}$, CPE: $1-8-\mathrm{CC}\left[\mathrm{C}^{\dagger} \mathrm{C}^{\dagger} \mathrm{F}^{\dagger}\right][\mathrm{FF}][\mathrm{FF}] \mathrm{F}^{\mathrm{TS}}\left[\mathrm{C}^{\dagger} \mathrm{C}^{\dagger}\right]-0: \mathbf{B D}+\mathrm{CO}$, and $\mathbf{B C H}: 1-8-\mathrm{CC}\left[\mathrm{C}^{\dagger} \mathrm{C}^{\dagger}\right] \mathrm{F}[\mathrm{FF}] \mathrm{F}^{\mathrm{TS}}\left[\mathrm{C}^{\dagger} \mathrm{C}^{\dagger}\right]-0$ : CD + CO. Breaking of $\mathrm{C}-\mathrm{C}$ bond between the terminal carbon atoms of diene/triene framework and carbon atom of $\mathrm{CO}$ fragment starts at distance of $c a$. 1.9-2.0 $\AA$ in the vicinity of the transition structure where the transition states are not reached yet. NCI analysis explains that the non-covalent interactions between two fragments are appeared after the breaking of $\mathrm{C}-\mathrm{C}$ bonds.
\end{abstract}

\footnotetext{
$\dagger$ Corresponding author. Tel: +98 912 2733755; Fax: +98 2332344634

E-mail addresses: e_zahedi@iau-shahrood.ac.ir; e_zahedi1357@yahoo.com
} 


\section{Introduction}

Molecular mechanism is understanding of bond breaking/forming, creation/annihilation of lone pairs, and electron rearrangement along the channel connecting reactant(s) with product(s) via the corresponding transition state for each elementary reaction ${ }^{1}$. Because of chemical bonds are not directly observable and measurable, elucidation of molecular mechanism can be provided by using physical observable functions supported by the Hohenberg-Kohn theorem (HKT) ${ }^{2-4}$. The quantum chemical topology (QCT) is the topological analysis of three-dimensional scalar fields such as electron density and its Laplacian, electron localization function (ELF), localized orbital locator (LOL), and molecular electrostatic potential which meet requirements for understanding of chemical structure and bonding ${ }^{5}$. ELF approach of Becke and Edgecombe ${ }^{6}$ which was developed for the study of electron pairing by Silvi and Savin ${ }^{7-9}$ depends on electronic density, its gradient, and the kinetic energy density. ELF performs a partition of system's space into basins and basins of attractors based on the gradients of particular scalar fields ${ }^{10}$. On the other hand, Rene Thom in the 1960's ${ }^{11}$ invented catastrophe theory (CT) which is as a special branch of dynamical system theory. According to the catastrophe theory, transition between successive structural stability domains (SSDs) along a reaction coordinate occurs at turning or bifurcation points ${ }^{12}$. Further development of ELF was proposed by Silvi and Krokidis 13 and the methodology is known as bonding evolution theory (BET). BET is the joint use of ELF and Thom's CT to demonstrate the molecular mechanism of a reaction in terms of creation or annihilation of electronic domains. The molecular mechanism of chemical reactions including Diels-Alder cycloaddition reaction ${ }^{14-26}$, cyclization reaction ${ }^{27,} 28$, Nazarov reaction ${ }^{29}$, SN2 reaction ${ }^{3}$, Cope and Claisen rearrangements ${ }^{30-32}$, Friedel-Crafts reaction ${ }^{33}$, Staudinger reaction 34,35 , ene reaction 36,37 , ring cleavage reaction ${ }^{38,39}$, trimerization reaction ${ }^{40},[3+2]$ cycloaddition reaction ${ }^{10,24,41-48}$, and [2+2] cycloaddition reaction ${ }^{49,50}$ have been studied in the BET framework. BET analysis has revealed that in some reactions the electron density does not flow in a cyclic, one-way curve meaning that evolution of chemical bonds are out a pericyclic mechanism ${ }^{15,16,31}$. In spite of the fact that cheletropic reactions are important class of pericyclic cycloaddition reactions, molecular mechanism of these reactions has so far received little attention and has been firstly attended by authors 51, 52. Recently, we investigated computationally the molecular mechanism of thermal cheletropic extrusion of $\mathrm{SO}_{2}$ from 1,3-dihydroisothianaphthene-2,2-dioxide

51 and

$\mathrm{N}_{2}$

from 
(2,5-dihydro-1Hpyrrol-1-ium-1-ylidene) amide ${ }^{52}$ using BET. Decarbonylation of cyclic ketones is a cycloreversion (fragmentation) reaction which is known as a cheletropic extrusion process. From the view point of orbital topology, decarbonylation of cyclic ketones can be classified into (i) pericyclic, orbital symmetry allowed reactions and (ii) pseudo-pericyclic reactions with orbital disconnection ${ }^{53,54}$. On the basis of the foregoing, it seems worthwhile to study the molecular mechanism of cheletropic decarbonylation of cyclic ketones by quantum interpretative techniques. Taking into account the mentioned topics, the purpose of this article is the study of the molecular mechanism for decarbonylation of unsaturated cyclic ketones of cyclohepta-3,5-dien-1-one CHD, cyclopent-3-en-1-one CPE and bicyclo[2.2.1]hept-2-en-7-one BCH (see Scheme 1) by means of the BET and non-covalent interaction (NCI) index ${ }^{55}$. The NCI index enables the study of the non-covalent interactions between atoms in a semi-quantitative and visual manner, so that the cross ELF/NCI analysis can provide a deeper insight into the understanding of reaction mechanisms ${ }^{2,56}$.

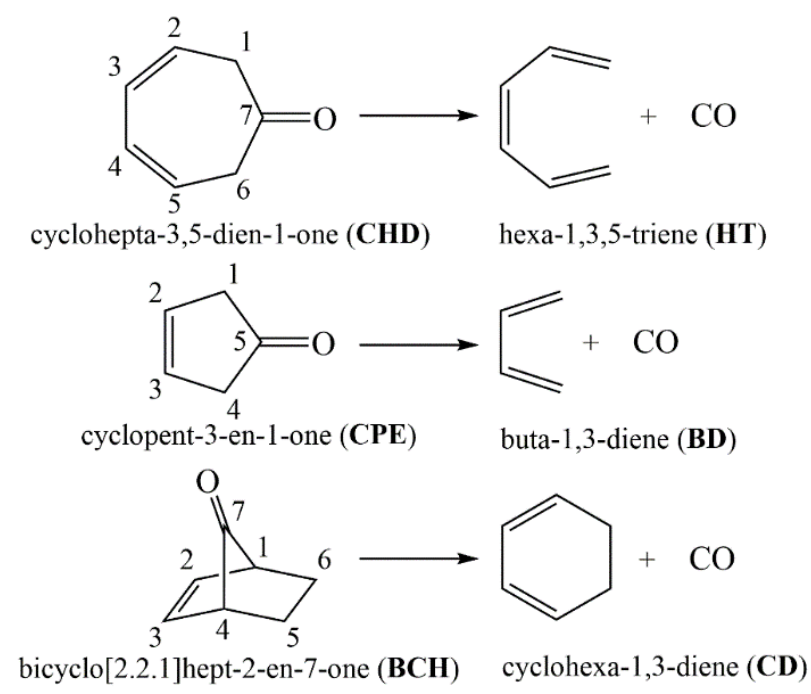

Scheme 1.

\section{Computational Details and Theoretical Background}

Density functional theory calculations were employed to study the cheletropic decarbonylation of CHD, CPE and BCH using Gaussian $09{ }^{57}$ suite of programs. For this purpose, the globalhybrid meta-generalized gradient approximation (GGA) functional MPWB1K ${ }^{58}$ in conjugation with Dunning's diffuse function augmented correlation-consistent triple- $\xi$ aug-cc-pVTZ basis 
set ${ }^{59}$ was employed in all calculations. MPWB1K functional is specially recommended for prediction of kinetic and thermodynamic parameters, gives excellent performance for noncovalent interactions ${ }^{58}$, and is widely used to study the molecular mechanism of different reactions ${ }^{45,47,48,60}$. This functional is not directly available in Gaussian 09 and requires an IOp command of $3 / 76=0560004400$ together with the MPWB95 functional ${ }^{58,61}$. Geometry optimization of reactants, transition states and products were performed with the Berny algorithm using the energy-represented direct inversion in the iterative subspace algorithm (GEDIIS) optimizer ${ }^{62}$. Intrinsic reaction coordinate (IRC) paths in mass-weighted Cartesian coordinates were generated for each reaction with a step size of $0.1 \mathrm{amu}^{1 / 2} \mathrm{Bohr}$ using the Hessian based predictor corrector (HPC) integrator algorithm proposed by Hratchian and Schlegel ${ }^{63}$ to verify the structure of transition states. For each point obtained on the IRC path, the wavefunction file was generated for the topological analysis; and also the global electrondensity transfer (GEDT) between the conjugated system and carbon monoxide was evaluated using the electrostatic Hirshfeld population analysis ${ }^{64}$.

The topological analysis of the ELF was carried out for each point on the IRC path using the TopMod program ${ }^{65}$ over a rectangular parallelepipedic box with a cubic grid of step size smaller than 0.1 Bohr and also was graphically represented by the Multiwfn suite of tools ${ }^{66}$. For a single determinental wavefunction built from orbital labelled $\varphi_{\mathrm{i}}$, spherically averaged like-spin conditional pair probability is related to the Fermi hole, and the ELF function $\eta(\mathbf{r})$ has values bounded between 0 and 1 . The ELF function is defined according to ${ }^{6}$ :

$$
\begin{aligned}
& \mathrm{ELF}=\eta(\mathbf{r})=\frac{1}{1+\left(\frac{D_{\sigma}(\mathbf{r})}{D_{\sigma}^{0}(\mathbf{r})}\right)^{2}} \\
& D_{\sigma}(\mathbf{r})=\sum_{i}^{\mathrm{Occ}}\left|\nabla \varphi_{i}(\mathbf{r})\right|^{2}-\frac{1}{4}\left[\frac{\left|\nabla \rho_{\alpha}(\mathbf{r})\right|^{2}}{\rho_{\alpha}(\mathbf{r})}+\frac{\left|\nabla \rho_{\beta}(\mathbf{r})\right|^{2}}{\rho_{\beta}(\mathbf{r})}\right] \\
& D_{\sigma}^{0}(\mathbf{r})=\frac{3}{5}\left(6 \pi^{2}\right)^{2 / 3}\left[\rho_{\alpha}(\mathbf{r})^{5 / 3}+\rho_{\beta}(\mathbf{r})^{5 / 3}\right]
\end{aligned}
$$

In above equations, $D_{\sigma}(\mathbf{r})$ is the excess of local kinetic energy density due to Pauli's repulsion, and $D_{\sigma}^{\mathrm{o}}(\mathbf{r})$ is the Thomas-Fermi kinetic energy density, which act as renormalization factor ${ }^{13}$. Upper limit of ELF corresponds to the single pair of electrons with antiparallel spins, i.e., perfect electron localization, while for electron-gas-like pair probability the corresponding value is 
equal to one half. Mathematical model of the ELF gradient field $\nabla \eta(\mathbf{r})$ provides a partition of the molecular space into basins of attractors that are considered as corresponding to atomic cores, bonds, and lone pairs ${ }^{10,67}$. In the mathematical field of dynamical systems, basin of an attractor is a region of the space phase containing the points that a steepest rise leads to the local maxima of ELF i.e. attractor. Basins can be classified into core basins, C(A), centered on atoms with atomic number $Z>2$, and valence basins. Valence basins also are distinguishable according to the their synaptic orders, i.e., monosynaptic basins, $\mathrm{V}(\mathrm{A})$, correspond to lone pairs or non-bonding regions, disynaptic basins, $\mathrm{V}(\mathrm{A}, \mathrm{B})$, correspond to the two-center bonds, protonated disynaptic basins, $\mathrm{V}(\mathrm{A}, \mathrm{H})$, correspond to bonds between hydrogen and an atom with atomic number $Z>2$, trisynaptic basins, $\mathrm{V}(\mathrm{A}, \mathrm{B}, \mathrm{C})$, correspond to three-center bonds and so on $\mathrm{V}(\mathrm{A}, \mathrm{B}, \mathrm{C}, \ldots)$ ) for higher polysynaptic basins ${ }^{67}$.

These classifying allow the calculation of average population for a basin labeled $\Omega_{\mathrm{A}}$ by integration of the density over $\Omega_{\mathrm{A}}$ as ${ }^{7}$ :

$$
\bar{N}\left(\Omega_{\mathrm{A}}\right)=\int_{\Omega_{\mathrm{A}}} \rho(\mathbf{r}) \mathrm{d} \mathbf{r}
$$

Using the basin population and its fluctuation, $\sigma^{2}(\bar{N} ; \Omega)$, relative fluctuation can be introduced which is the quantum-mechanical measure of delocalization of electron density ${ }^{7}$ :

$$
\lambda(\Omega)=\frac{\sigma^{2}(\bar{N} ; \Omega)}{\bar{N}(\Omega)}
$$

For a superbasin $\Omega_{A} \cup \Omega_{B}$ :

$$
\sigma^{2}(\bar{N} ; \Omega)=\sigma^{2}\left(\bar{N} ; \Omega_{A}\right)+\sigma^{2}\left(\bar{N} ; \Omega_{B}\right)-2 B\left(\Omega_{A}, \Omega_{B}\right)
$$

and

$$
\bar{N}(\Omega)=\bar{N}\left(\Omega_{A}\right)+\bar{N}\left(\Omega_{B}\right)
$$

where, $B\left(\Omega_{A}, \Omega_{B}\right)$ is interbasin integrated exchange density.

Following of basin populations along the reaction path define electronic charge flows along a reaction and allow to characterize the molecular mechanism by a sequence of elementary catastrophes cusp $\left(\mathrm{C}\right.$ and $\left.\mathrm{C}^{\dagger}\right)$ and fold $\left(\mathrm{F}\right.$ and $\left.\mathrm{F}^{\dagger}\right)$. The $\mathrm{C}$ (or $\mathrm{F}$ ) catastrophe merges two attractors (an attractor) and a saddle point into an attractor (a wandering point) i.e. decreasing the number of basins by 1 , while the $\mathrm{C}^{\dagger}$ (or $\mathrm{F}^{\dagger}$ ) catastrophe splits an attractor (a wandering point) into two attractors (an attractor) and a saddle point i.e. increasing of the number of basins by $1^{5,13,50}$. 
The NCI approach has been performed for each point on the IRC path using NCIPLOT code developed by Johnson and co-workers ${ }^{55}$ with utilization of the self-consistent field (SCF) densities. The NCI technique rests on the normalized and dimensionless reduced density gradient (RDG), $s(\rho)$, as a scalar function to describe the deviation from a homogeneous electron distribution. This function coming from the electron density, $\rho$, and its gradient, $\nabla \rho$, has been defined by ${ }^{68}$ :

$$
s(\rho)=\frac{|\nabla \rho|}{2 \sqrt[3]{3 \pi^{2} \rho^{4}}}
$$

$\mathrm{NCI}$ approach is able to characterize attractive or repulsive interactions between atoms according to the topology of the electron density ${ }^{69}$. To differentiate between the stabilizing and destabilizing interactions the Laplacian of the electron density, $\nabla^{2} \rho$, along the main axis of variation should be examined. The contributions to the Laplacian are the eigenvalues of electron density (second derivative) Hessian matrix as $\nabla^{2} \rho=\lambda_{1}+\lambda_{2}+\lambda_{3}$, where $\lambda_{1}<\lambda_{2}<\lambda_{3}$. The sign of second eigenvalue $\left(\lambda_{2}\right)$ can determine the type of interaction in plotting of RDG as a function of electron density (2D NCI plots) ${ }^{55,68}$. Also, a RGB coloring scheme has been used to distinguish between different types of interactions in the 3D NCI plots by the following color codes:

- blue isosurfaces for strong attractive interactions

- green isosurfaces for weak (van der Waals) interactions

- red isosurfaces for strong repulsive interactions or non-bonded overlap

NCI plots were generated with a 0.1 a.u. step size on cuboid grids and default options of NCI code were also selected for other variable parameters.

\section{Results and Discussion}

The optimized geometries of reactants, TSs and products involved in the decarbonylation reactions of $\mathbf{C H D}, \mathbf{C P E}$ and $\mathbf{B C H}$ including the lengths of the breaking bonds and imaginary frequencies of TSs are shown in Figure 1. The predicted activation barriers at 0K, including electronic and zero-point vibrational energies, are 228.3, 236.3, and $160.7 \mathrm{~kJ}^{\mathrm{mol}}{ }^{-1}$ for CHD, CPE and $\mathbf{B C H}$, respectively. The experimental values of infinite pressure activation energies at temperatures higher than $1100 \mathrm{~K}$ are $255 \pm 10,194 \pm 10$, and $146 \pm 6 \mathrm{~kJ} \cdot \mathrm{mol}^{-1}$, respectively ${ }^{70}$. 

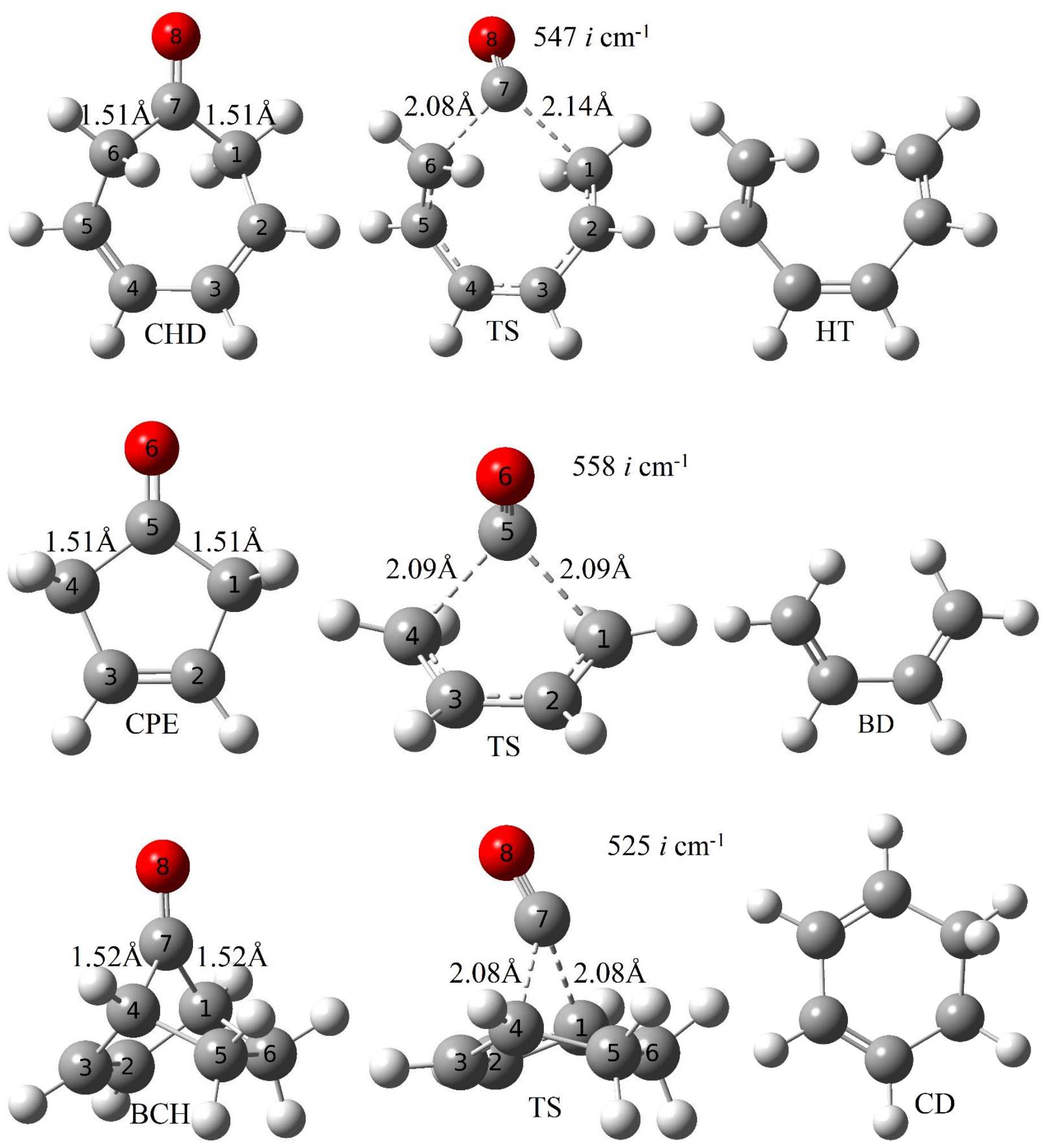

Figure 1. MPWB1K/aug-cc-pVTZ geometries of reactants, TSs and products associated with the decarbonylations of $\mathbf{C H D}, \mathbf{C P E}$ and $\mathbf{B C H}$, including the lengths of the breaking bonds and imaginary frequencies of TSs. 
The calculated GEDT at the TS associated with the decarbonylation of CHD shows that there is no net charge transfer, while for TSs associated with the decarbonylation of CPE and BCH GEDT values are 0.02, and 0.03 e which flux from $\mathrm{CO}$ toward diene framework. These values allow to classify the studied decarbonylations as non-polar cheletropic extrusion reactions. The energy profiles along the reaction coordinate together with the position of each turning points representing the SSDs, and Lewis type representations of each domain, separated by the fold and cusp catastrophes of ELF, are reported for the thermal decarbonylations of CHD, CPE and BCH in Figures 2-4, respectively. The color-filled maps of the ELF in the molecular plane involved the bond breaking, and snapshots of the ELF localization domains are also included in Figures 24 for the reactants and related TSs. For each turning points obtained on the IRC pathways, the color-filled maps of the ELF and snapshots of the ELF localization domains are sketched in Figures S1-S3 (see supporting information). The population of the ELF valence basins for the reactants, each of turning points and products are gathered in Tables 1-3 for the decarbonylations of $\mathbf{C H D}, \mathbf{C P E}$ and $\mathbf{B C H}$, respectively.

The thermal decarbonylation of CHD can be characterized by SSDs associated to the sequence of catastrophes CHD: $1-11-\mathrm{C}[\mathrm{CC}] \mathrm{C}^{\dagger} \mathrm{C}^{\dagger} \mathrm{FFF}^{\mathrm{TS}} \mathrm{C}^{\dagger} \mathrm{C}^{\dagger} \mathrm{C}^{\dagger}-0$ : HT $+\mathrm{CO}$. The first SSD, $1.509 \leq d$ $\mathrm{C}_{1}-\mathrm{C}_{7}(\AA)<1.514$ and $1.509 \leq d \mathrm{C}_{6}-\mathrm{C}_{7}(\AA)<1.504$, starts exactly at the point where the CHD enters into the reaction channel and finishes before P1 point. The ELF topology of SSD I is the same with the reactant and is characterized by eleven valence bonding disynaptic and two monosynaptic basins. The ELF topology of CHD presents two disynaptic basins $\mathrm{V}\left(\mathrm{C}_{1}-\mathrm{C}_{7}\right)$, and $\mathrm{V}\left(\mathrm{C}_{6}-\mathrm{C}_{7}\right)$ associated with the $\mathrm{C}_{1}-\mathrm{C}_{7}$, and $\mathrm{C}_{6}-\mathrm{C}_{7}$ single bonds, respectively with the values of the basin population $2.03 \overline{\mathrm{e}}$ and relative fluctuation 0.51 for each one; two disynaptic basins $\mathrm{V}$ $\left(\mathrm{C}_{1}-\mathrm{C}_{2}\right)$, and $\mathrm{V}\left(\mathrm{C}_{5}-\mathrm{C}_{6}\right)$ associated with the $\mathrm{C}_{1}-\mathrm{C}_{2}$ and $\mathrm{C}_{5}-\mathrm{C}_{6}$ single bonds, respectively with the values of the basin population $2.05 \overline{\mathrm{e}}$ and relative fluctuation 0.53 for each one; two disynaptic basins $\mathrm{V}\left(\mathrm{C}_{2}-\mathrm{C}_{3}\right)$ and $\mathrm{V}^{\prime}\left(\mathrm{C}_{2}-\mathrm{C}_{3}\right)$ associated with the $\mathrm{C}_{2}=\mathrm{C}_{3}$ double bond, integrating to $3.36 \overline{\mathrm{e}}$ $(1.76 \overline{\mathrm{e}}+1.60 \overline{\mathrm{e}})$, with the relative fluctuation 0.60 ; two disynaptic basins $\mathrm{V}\left(\mathrm{C}_{4}-\mathrm{C}_{5}\right)$ and $\mathrm{V}^{\prime}$ $\left(\mathrm{C}_{4}-\mathrm{C}_{5}\right)$ associated with the $\mathrm{C}_{4}=\mathrm{C}_{5}$ double bond, integrating to $3.36 \overline{\mathrm{e}}(1.76 \overline{\mathrm{e}}+1.60 \overline{\mathrm{e}})$, with the relative fluctuation 0.60 ; one disynaptic basins $\mathrm{V}\left(\mathrm{C}_{3}-\mathrm{C}_{4}\right)$ associated with the $\mathrm{C}_{3}-\mathrm{C}_{4}$ single bond with the values of the basin population $2.25 \overline{\mathrm{e}}$ and relative fluctuation 0.54 ; two disynaptic basins $\mathrm{V}\left(\mathrm{C}_{7}-\mathrm{O}\right)$ and $\mathrm{V}^{\prime}\left(\mathrm{C}_{7}-\mathrm{O}\right)$ associated with the $\mathrm{C}_{7}=\mathrm{O}$ double bond, integrating to $2.47 \overline{\mathrm{e}}(1.27 \overline{\mathrm{e}}+$ 
$1.20 \overline{\mathrm{e}}$ ), with the relative fluctuation 0.71 ; and two monosynaptic basins $\mathrm{V}(\mathrm{O})$ and $\mathrm{V}^{\prime}(\mathrm{O})$ associated with the located lone pairs on the oxygen atom, integrating to $5.21 \overline{\mathrm{e}}(2.61 \overline{\mathrm{e}}+2.60 \overline{\mathrm{e}})$, with the relative fluctuation 0.44 for each one. The values of the relative fluctuation for $C_{2}=C_{3}$ and $\mathrm{C}_{4}=\mathrm{C}_{5}$ bonds are very close to carbon-carbon bonds in benzene (as reference: $\lambda=0.61$ ) and for $\mathrm{C}_{7}=\mathrm{O}$ bond is larger than both of them, meaning that the electron density in $\mathrm{C}_{7}=\mathrm{O}$ bond is greatly delocalized with respect to carbon-carbon bonds in benzene, while for $C_{2}=C_{3}$ and $C_{4}=C_{5}$ bonds is approximately equal to carbon-carbon bonds in benzene. The relative fluctuation value for other carbon-carbon single bonds are smaller than benzene ring and electron density in these basins are delocalized to a smaller degree than benzene ring. This is while the monosynaptic basins of oxygen atom are localized with respect to valence disynaptic basins in CHD. The character of the single bonds $\mathrm{C}_{1}-\mathrm{C}_{2}, \mathrm{C}_{5}-\mathrm{C}_{6}, \mathrm{C}_{1}-\mathrm{C}_{7}$, and $\mathrm{C}_{6}-\mathrm{C}_{7}$ are confirmed by their populations which are very close to the formal value of $2 \overline{\mathrm{e}}$, while $\mathrm{C}_{3}-\mathrm{C}_{4}$ is an electron-rich single bond with $0.25 \bar{e}$ more than the formal value. Formal double bonds of $\mathrm{C}_{2}=\mathrm{C}_{3}, \mathrm{C}_{4}=\mathrm{C}_{5}$ and $\mathrm{C}_{7}=\mathrm{O}$ are described by two attractors and their populations are less than the formal value of $4 \overline{\mathrm{e}}$. The missing electron density in the electron-depleted double bonds are located on $\mathrm{V}\left(\mathrm{C}_{3}-\mathrm{C}_{4}\right)$ valence basin and nonbonding $\mathrm{V}(\mathrm{O})$ and $\mathrm{V}^{\prime}(\mathrm{O})$ basins. The electron-depleted $\mathrm{C}_{7}=\mathrm{O}$ double bond, electron-rich nonbonding basins of oxygen atom and positive charge of $\mathrm{C}_{7}$ carbon atom indicate that the carbon-oxygen bond is highly polarized with a large weight of resonance hybrid 2 (see Scheme 2). The electrostatic Hirshfeld population analysis indicates that the GEDT equal to 0.09 e fluxes from $\mathrm{CO}$ to the HT fragment.

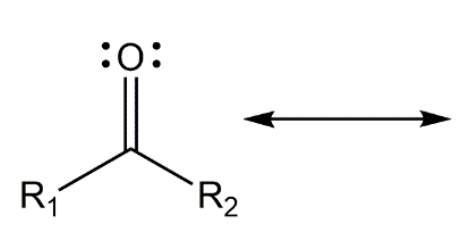

(1)

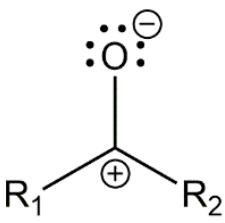

(2)

Scheme 2. Two resonance forms of carbonyl group. 

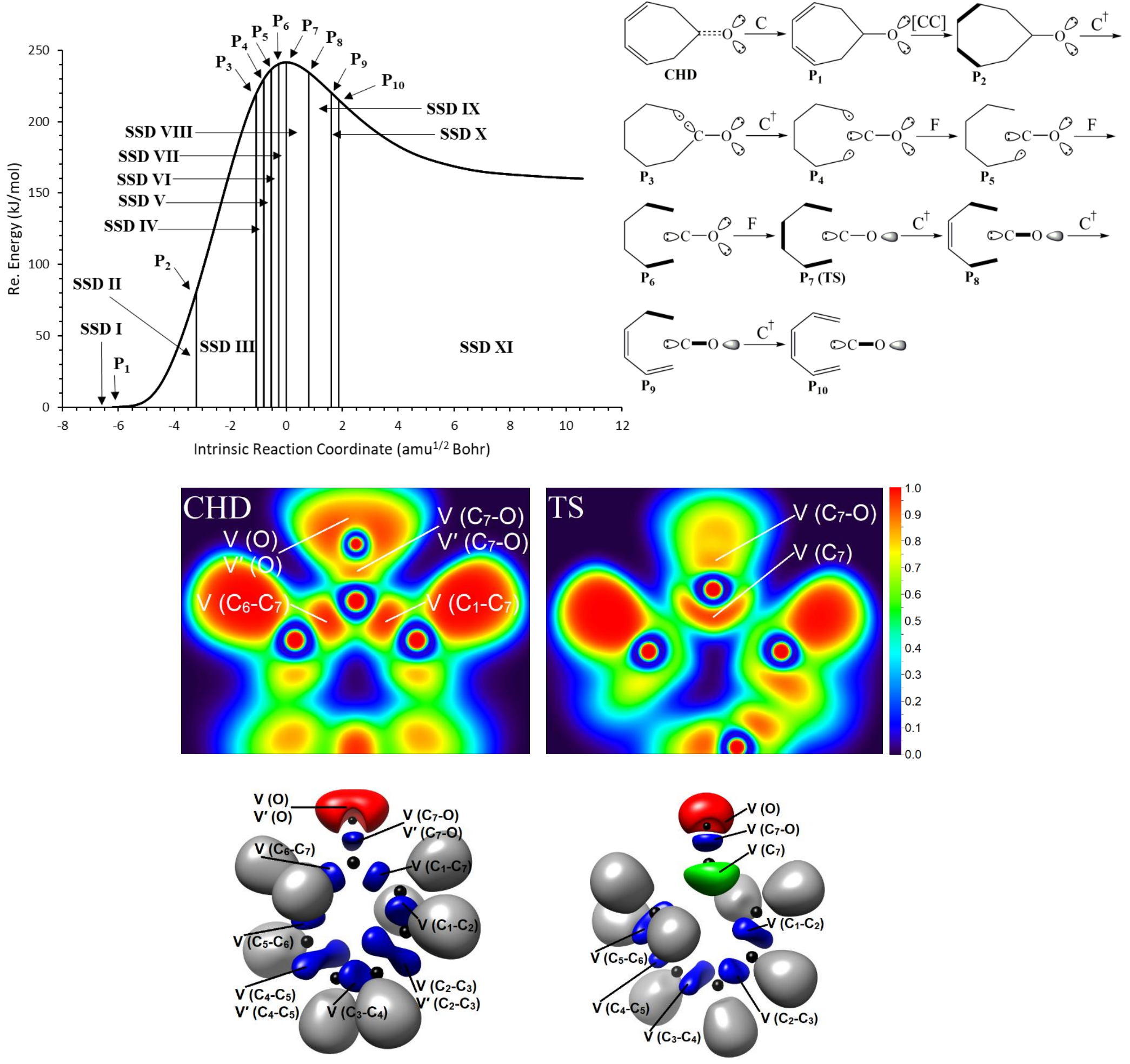

Figure 2. Top of the graph, energy profile for decarbonylation reaction of CHD with marked SSDs obtained from the ELF topological analysis; and Lewis type representation of the reaction mechanism (Bold bonds represent partial double bonds, filled ellipses indicate LPs monosynaptic basins with a population larger than $4.0 \overline{\mathrm{e}}$, and small ellipses with one dot indicate non-bonding pseudoradical centers). Below the graph, color-filled maps of the ELF (in the molecular plane defined by plane of the $\mathrm{C}_{1}-\mathrm{C}_{6}-\mathrm{C}_{7}$ ) and snapshots of the ELF localization domains $(\eta=0.8-0.81$; Color code: black for core basins, grey for protonated disynaptic basins, blue for disynaptic basins, red for LPs monosynaptic basins of $\mathrm{O}$ atom, and green for LPs monosynaptic basins of $\mathrm{C}$ atom) for reactant and TS. 
Table 1. Integrated ELF basin populations in different SSDs along the decarbonylation reaction of CHD calculated at the MPWB1K/aug-cc-pVTZ level. The GEDT stands for global electron-density transfer ( $\overline{\mathrm{e}})$ obtained from triene fragment.

\begin{tabular}{|c|c|c|c|c|c|c|c|c|c|c|c|c|}
\hline SSD & & & SSD II & SSD III & SSD IV & SSD V & SSD VI & SSD VII & SSD VIII & SSD IX & SSD X & \\
\hline Points & CHD & $\mathbf{P}_{1}$ & $\mathbf{P}_{2}$ & $\mathbf{P}_{3}$ & $\mathbf{P}_{4}$ & $\mathbf{P}_{5}$ & $\mathbf{P}_{6}$ & $\mathbf{P}_{7}$ & $\mathbf{P}_{8}$ & $\mathbf{P}_{9}$ & $\mathbf{P}_{10}$ & $\mathrm{HT}+\mathrm{CO}$ \\
\hline$d \mathrm{C}_{1}-\mathrm{C}_{7}(\AA)$ & 1.509 & 1.514 & 1.739 & 2.008 & 2.041 & 2.074 & 2.106 & 2.139 & 2.238 & 2.338 & 2.372 & - \\
\hline$d \mathrm{C}_{6}-\mathrm{C}_{7}(\AA)$ & 1.509 & 1.504 & 1.673 & 1.935 & 1.971 & 2.006 & 2.041 & 2.076 & 2.181 & 2.286 & 2.321 & - \\
\hline GEDT & 0.09 & 0.09 & 0.05 & 0.01 & 0.00 & 0.00 & 0.00 & 0.00 & 0.00 & 0.00 & 0.00 & - \\
\hline $\mathrm{V}\left(\mathrm{C}_{1}-\mathrm{C}_{2}\right)$ & 2.05 & 2.07 & 2.16 & 2.60 & 2.72 & 2.97 & 3.01 & 3.04 & 3.16 & 3.23 & 1.74 & 1.74 \\
\hline $\mathrm{V}^{\prime}\left(\mathrm{C}_{1}-\mathrm{C}_{2}\right)$ & - & - & - & - & - & - & - & - & - & - & 1.50 & 1.62 \\
\hline $\mathrm{V}\left(\mathrm{C}_{2}-\mathrm{C}_{3}\right)$ & 1.76 & 1.73 & 3.27 & 2.88 & 2.77 & 2.67 & 2.58 & 2.51 & 2.36 & 2.29 & 2.27 & 2.20 \\
\hline $\mathrm{V}^{\prime}\left(\mathrm{C}_{2}-\mathrm{C}_{3}\right)$ & 1.60 & 1.62 & - & - & - & - & - & - & - & - & - & - \\
\hline $\mathrm{V}\left(\mathrm{C}_{3}-\mathrm{C}_{4}\right)$ & 2.25 & 2.25 & 2.32 & 2.69 & 2.79 & 2.89 & 2.97 & 3.05 & 1.61 & 1.64 & 1.65 & 1.69 \\
\hline $\mathrm{V}^{\prime}\left(\mathrm{C}_{3}-\mathrm{C}_{4}\right)$ & - & - & - & - & - & - & - & - & 1.58 & 1.64 & 1.65 & 1.69 \\
\hline $\mathrm{V}\left(\mathrm{C}_{4}-\mathrm{C}_{5}\right)$ & 1.76 & 1.77 & 3.29 & 2.92 & 2.81 & 2.70 & 2.61 & 2.53 & 2.38 & 2.30 & 2.27 & 2.20 \\
\hline $\mathrm{V}^{\prime}\left(\mathrm{C}_{4}-\mathrm{C}_{5}\right)$ & 1.60 & 1.59 & - & - & - & - & - & - & - & - & - & - \\
\hline $\mathrm{V}\left(\mathrm{C}_{5}-\mathrm{C}_{6}\right)$ & 2.05 & 2.03 & 2.10 & 2.53 & 2.65 & 2.79 & 3.01 & 3.05 & 3.16 & 1.50 & 1.74 & 1.74 \\
\hline $\mathrm{V}^{\prime}\left(\mathrm{C}_{5}-\mathrm{C}_{6}\right)$ & - & - & - & - & - & - & - & - & - & 1.72 & 1.50 & 1.62 \\
\hline $\mathrm{V}\left(\mathrm{C}_{1}-\mathrm{C}_{7}\right)$ & 2.03 & 2.04 & 1.90 & - & - & - & - & - & - & - & - & - \\
\hline $\mathrm{V}\left(\mathrm{C}_{6}-\mathrm{C}_{7}\right)$ & 2.03 & 2.03 & 1.92 & 1.38 & - & - & - & - & - & - & - & - \\
\hline $\mathrm{V}\left(\mathrm{C}_{7}-\mathrm{O}\right)$ & 1.27 & 2.42 & 2.50 & 2.70 & 2.76 & 2.80 & 2.84 & 2.89 & 2.98 & 3.03 & 3.04 & 3.16 \\
\hline $\mathrm{V}^{\prime}\left(\mathrm{C}_{7}-\mathrm{O}\right)$ & 1.20 & - & - & - & - & - & - & - & - & - & - & - \\
\hline $\mathrm{V}(\mathrm{O})$ & 2.61 & 2.59 & 2.56 & 2.41 & 2.38 & 2.33 & 2.30 & 4.54 & 4.43 & 4.36 & 4.35 & 4.18 \\
\hline $\mathrm{V}^{\prime}(\mathrm{O})$ & 2.60 & 2.58 & 2.54 & 2.37 & 2.34 & 2.32 & 2.29 & - & - & - & - & - \\
\hline $\mathrm{V}\left(\mathrm{C}_{1}\right)$ & - & - & - & 0.31 & 0.23 & - & - & - & - & - & - & - \\
\hline$V\left(C_{6}\right)$ & - & - & - & - & 0.27 & 0.19 & - & - & - & - & - & - \\
\hline $\mathrm{V}\left(\mathrm{C}_{7}\right)$ & - & - & - & 1.46 & 2.48 & 2.46 & 2.46 & 2.46 & 2.46 & 2.47 & 2.46 & 2.49 \\
\hline
\end{tabular}


The second SSD, $1.514 \leq d \mathrm{C}_{1}-\mathrm{C}_{7}(\AA)<1.739$ and $1.504 \leq d \mathrm{C}_{6}-\mathrm{C}_{7}(\AA)<1.673$, starts from $\mathbf{P}_{1}$ point at $\mathrm{Rx}=-5.970 \mathrm{amu}{ }^{1 / 2} \mathrm{Bohr}$ and ends before $\mathbf{P}_{2}$ point with the cusp $(\mathrm{C})$ type catastrophe in the $\mathrm{C}_{7}=\mathrm{O}$ bond. Two disynaptic basins $\mathrm{V}\left(\mathrm{C}_{7}-\mathrm{O}\right)$ and $\mathrm{V}^{\prime}\left(\mathrm{C}_{7}-\mathrm{O}\right)$ are merged into a single basin $\mathrm{V}$ $\left(\mathrm{C}_{7}-\mathrm{O}\right)$ with the basin population $2.42 \overline{\mathrm{e}}$ at $\mathbf{P}_{1}$ point. This SSD entails an energetic cost of 80.6 kJ.mol ${ }^{-1}$; and the GEDT at $\mathbf{P}_{1}$ point is unchanged. The third SSD, $1.739 \leq d \mathrm{C}_{1}-\mathrm{C}_{7}(\AA)<2.008$ and $1.673 \leq d \mathrm{C}_{6}-\mathrm{C}_{7}(\AA)<1.935$, begins from $\mathbf{P}_{2}$ point at $\mathrm{Rx}=-3.215 \mathrm{amu}^{1 / 2} \mathrm{Bohr}$ and completes before $\mathbf{P}_{3}$ point with two simultaneous cusp (CC) type catastrophes in the region of $\mathrm{C}_{2}=\mathrm{C}_{3}$ and $\mathrm{C}_{4}=\mathrm{C}_{5}$ bonds. At the beginning of the SSD III, the GEDT is decreased to $0.05 \overline{\mathrm{e}}$ and disynaptic basin pairs of $\mathrm{V}\left(\mathrm{C}_{2}-\mathrm{C}_{3}\right), \mathrm{V}^{\prime}\left(\mathrm{C}_{2}-\mathrm{C}_{3}\right)$ and $\mathrm{V}\left(\mathrm{C}_{4}-\mathrm{C}_{5}\right), \mathrm{V}^{\prime}\left(\mathrm{C}_{4}-\mathrm{C}_{5}\right)$ are joined into single basins $\mathrm{V}\left(\mathrm{C}_{2}-\mathrm{C}_{3}\right)$ and $\mathrm{V}\left(\mathrm{C}_{4}-\mathrm{C}_{5}\right)$ with the basin populations $3.27 \overline{\mathrm{e}}$ and $3.29 \overline{\mathrm{e}}$, respectively. It is worth noting that the SSD III is the most costly SSD in term of energy with an increment of

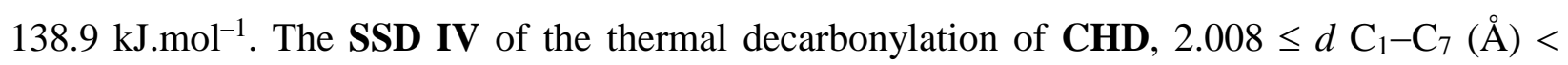
2.041 and $1.935 \leq d \mathrm{C}_{6}-\mathrm{C}_{7}(\AA)<1.971$, begins with a cusp $\left(\mathrm{C}^{\dagger}\right)$ type catastrophe from $\mathbf{P}_{3}$ point at $\mathrm{Rx}=-1.071 \mathrm{amu}^{1 / 2}$ Bohr and finishes before $\mathbf{P}_{4}$ point with an increment of $9.9 \mathrm{~kJ}_{\mathrm{mol}}{ }^{-1}$ in energy. The valence disynaptic basin $\mathrm{V}\left(\mathrm{C}_{1}-\mathrm{C}_{7}\right)$ is transformed into two monosynaptic basins $\mathrm{V}$ $\left(\mathrm{C}_{1}\right)$ and $\mathrm{V}\left(\mathrm{C}_{7}\right)$ corresponding to the homolitic bond cleavage. It should be noted that both monosynaptic basins are found in the bonding region and associated to the pseudoradical centers on the $\mathrm{C}_{1}$ atom with $0.31 \overline{\mathrm{e}}$ and on the $\mathrm{C}_{7}$ atom with $1.48 \mathrm{e}$. At the starting point of this $\mathrm{SSD}$, the valence basin populations are changed significantly, in such a manner that basin populations of $\mathrm{V}\left(\mathrm{C}_{1}-\mathrm{C}_{2}\right), \mathrm{V}\left(\mathrm{C}_{3}-\mathrm{C}_{4}\right), \mathrm{V}\left(\mathrm{C}_{5}-\mathrm{C}_{6}\right)$ and the basin populations of $\mathrm{V}\left(\mathrm{C}_{2}-\mathrm{C}_{3}\right), \mathrm{V}\left(\mathrm{C}_{4}-\mathrm{C}_{5}\right), \mathrm{V}\left(\mathrm{C}_{6}-\mathrm{C}_{7}\right)$ are increased and decreased, respectively in the range of $0.37-0.44 \overline{\mathrm{e}}$, also a GEDT $0.01 \mathrm{e}$ takes place from CO to the HT fragment. The SSD V, $2.041 \leq d \mathrm{C}_{1}-\mathrm{C}_{7}(\AA)<2.074$ and $1.971 \leq d$ $\mathrm{C}_{6}-\mathrm{C}_{7}(\AA)<2.006$, takes place from $\mathbf{P}_{4}$ point at $\mathrm{Rx}=-0.803 \mathrm{amu}^{1 / 2}$ Bohr and ends before $\mathbf{P}_{5}$ point. From the beginning of this SSD to the end of the reaction no charge transfer takes place between two fragments. The SSD V entails an energetic cost of $6.8 \mathrm{~kJ}^{\mathrm{m}} \mathrm{mol}^{-1}$ and is started with a cusp $\left(\mathrm{C}^{\dagger}\right)$ type catastrophe associated with the $\mathrm{C}_{6}-\mathrm{C}_{7}$ bond breaking. The valence disynaptic basin $\mathrm{V}\left(\mathrm{C}_{6}-\mathrm{C}_{7}\right)$ is transformed into a monosynaptic basin $\mathrm{V}\left(\mathrm{C}_{6}\right)$ with a basin population of 0.27 $\overline{\mathrm{e}}$ and the residual electrons of disynaptic basin $\mathrm{V}\left(\mathrm{C}_{6}-\mathrm{C}_{7}\right)$ has been transferred to the monosynaptic basin $\mathrm{V}\left(\mathrm{C}_{7}\right)$. It is worth noting that the position of the monosynaptic basin $\mathrm{V}\left(\mathrm{C}_{7}\right)$, with a basin population of $2.48 \overline{\mathrm{e}}$, is changed from the initial position, $\mathrm{C}_{1}-\mathrm{C}_{7}$ bonding region, to a 
new position where nonbonding lone electron pair of carbon atom in $\mathrm{CO}$ fragment is expected. Two consecutive SSDs VI, $2.074 \leq d \mathrm{C}_{1}-\mathrm{C}_{7}(\AA)<2.106$ and $2.006 \leq d \mathrm{C}_{6}-\mathrm{C}_{7}(\AA)<2.041$, and VII, $2.106 \leq d \mathrm{C}_{1}-\mathrm{C}_{7}(\AA)<2.139$ and $2.041 \leq d \mathrm{C}_{6}-\mathrm{C}_{7}(\AA)<2.076$, begin with the fold (F) type catastrophe at $\mathrm{Rx}=-0.535 \mathrm{amu}^{1 / 2} \mathrm{Bohr}$ and $\mathrm{Rx}=-0.267 \mathrm{amu}^{1 / 2} \mathrm{Bohr}$, respectively. These SSDs are energetically low cost and exhibit annihilation of nonbonding monosynaptic basins $\mathrm{V}\left(\mathrm{C}_{1}\right)$ and $\mathrm{V}\left(\mathrm{C}_{6}\right)$, respectively by transferring of their electrons into the other disynaptic basins such as $\mathrm{V}\left(\mathrm{C}_{1}-\mathrm{C}_{2}\right), \mathrm{V}\left(\mathrm{C}_{3}-\mathrm{C}_{4}\right)$, and $\mathrm{V}\left(\mathrm{C}_{5}-\mathrm{C}_{6}\right)$. The SSD VIII, $2.139 \leq d \mathrm{C}_{1}-\mathrm{C}_{7}(\AA)<2.238$ and $2.076 \leq$ $d \mathrm{C}_{6}-\mathrm{C}_{7}(\AA)<2.181$, starts with a fold $(\mathrm{F})$ type catastrophe at the point where the TS is reached. From the view point of molecular mechanism, this SSD is very important because it can characterize the topology of the TS. It should be noted that at TS the $\mathrm{C}_{1}-\mathrm{C}_{7}$ and $\mathrm{C}_{6}-\mathrm{C}_{7}$ bonds are completely broken in the TS, and the reaction continues by merging of nonbonding monosynaptic basins $\mathrm{V}(\mathrm{O})$ and $\mathrm{V}^{\prime}(\mathrm{O})$ into a new monosynaptic basin $\mathrm{V}(\mathrm{O})$ with a basin

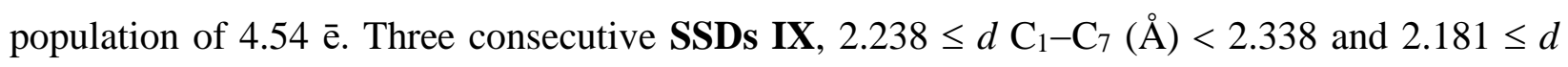
$\mathrm{C}_{6}-\mathrm{C}_{7}(\AA)<2.286, \mathbf{X}, 2.338 \leq d \mathrm{C}_{1}-\mathrm{C}_{7}(\AA)<2.372$ and $2.286 \leq d \mathrm{C}_{6}-\mathrm{C}_{7}(\AA)<2.321$, and $\mathbf{X I}$, $2.372 \leq d \mathrm{C}_{1}-\mathrm{C}_{7}(\AA)$ and $2.321 \leq d \mathrm{C}_{6}-\mathrm{C}_{7}(\AA)$, are started with the cusp $\left(\mathrm{C}^{\dagger}\right)$ type catastrophe at $\mathrm{Rx}=0.803 \mathrm{amu}^{1 / 2} \mathrm{Bohr}, \mathrm{Rx}=1.607 \mathrm{amu}^{1 / 2}$ Bohr and $\mathrm{Rx}=1.875 \mathrm{amu}^{1 / 2}$ Bohr, respectively. In the related turning points, the cusp $\left(\mathrm{C}^{\dagger}\right)$ type catastrophes lead to the formation of $\mathrm{C}_{3}=\mathrm{C}_{4}, \mathrm{C}_{5}=\mathrm{C}_{6}$, and $\mathrm{C}_{1}=\mathrm{C}_{2}$ double bonds, respectively. At the end of the reaction, the hexa-1,3,5-triene HT is formed and completely separated from CO molecule.

The ELF topology of HT exhibits two pairs disynaptic basins $\mathrm{V}\left(\mathrm{C}_{1}-\mathrm{C}_{2}\right), \mathrm{V}^{\prime}\left(\mathrm{C}_{1}-\mathrm{C}_{2}\right)$ and $\mathrm{V}$ $\left(\mathrm{C}_{5}-\mathrm{C}_{6}\right), \mathrm{V}^{\prime}\left(\mathrm{C}_{5}-\mathrm{C}_{6}\right)$ associated with the $\mathrm{C}_{1}=\mathrm{C}_{2}$ and $\mathrm{C}_{5}=\mathrm{C}_{6}$ double bonds, respectively, integrating to $3.36 \overline{\mathrm{e}}(1.74 \overline{\mathrm{e}}+1.62 \overline{\mathrm{e}})$ with relative fluctuation 0.60 for each bonds; two disynaptic basins $\mathrm{V}\left(\mathrm{C}_{2}-\mathrm{C}_{3}\right)$ and $\mathrm{V}\left(\mathrm{C}_{4}-\mathrm{C}_{5}\right)$ associated with the $\mathrm{C}_{2}-\mathrm{C}_{3}$ and $\mathrm{C}_{4}-\mathrm{C}_{5}$ single bonds with the values of the basin population $2.20 \overline{\mathrm{e}}$ and relative fluctuation 0.53 for each one; and two disynaptic basins $\mathrm{V}\left(\mathrm{C}_{3}-\mathrm{C}_{4}\right), \mathrm{V}^{\prime}\left(\mathrm{C}_{3}-\mathrm{C}_{4}\right)$ associated with the $\mathrm{C}_{3}=\mathrm{C}_{4}$ double bond, integrating to $3.38 \overline{\mathrm{e}}(1.69 \overline{\mathrm{e}}+1.69 \overline{\mathrm{e}})$ with relative fluctuation 0.59 . Basin populations indicate that $\mathrm{C}_{1}-\mathrm{C}_{2}$, $\mathrm{C}_{3}-\mathrm{C}_{4}$, and $\mathrm{C}_{5}-\mathrm{C}_{6}$ bonds have been saturated during the reaction course by $1.31 \overline{\mathrm{e}}, 1.13 \overline{\mathrm{e}}$, and $1.31 \overline{\mathrm{e}}$, respectively, while $\mathrm{C}_{2}-\mathrm{C}_{3}$ and $\mathrm{C}_{4}-\mathrm{C}_{5}$ bonds have been depopulated by $1.16 \overline{\mathrm{e}}$ for each one. On the other hand, the relative fluctuation values show that the delocalization degree for 
$\mathrm{C}_{1}=\mathrm{C}_{2}, \mathrm{C}_{5}=\mathrm{C}_{6}$, and $\mathrm{C}_{3}=\mathrm{C}_{4}$ double bonds is approximately equal to benzene, while the electron density in $\mathrm{C}_{2}-\mathrm{C}_{3}$ and $\mathrm{C}_{4}-\mathrm{C}_{5}$ single bonds are less delocalized in comparison with benzene ring. The thermal decarbonylation of CPE can be described by SSDs associated to the sequence of catastrophes CPE: $1-8-\mathrm{CC}\left[\mathrm{C}^{\dagger} \mathrm{C}^{\dagger} \mathrm{F}^{\dagger}\right][\mathrm{FF}][\mathrm{FF}] \mathrm{F}^{\mathrm{TS}}\left[\mathrm{C}^{\dagger} \mathrm{C}^{\dagger}\right]-0$ : BD + CO. The first SSD, $1.514 \leq d$ $\mathrm{C}_{1,4}-\mathrm{C}_{5}(\AA)<1.512$, starts where the ELF topology is the same with CPE, with eight valence bonding disynaptic and two monosynaptic basins. The ELF topology of CPE consists of two disynaptic basins $\mathrm{V}\left(\mathrm{C}_{1}-\mathrm{C}_{5}\right)$, and $\mathrm{V}\left(\mathrm{C}_{4}-\mathrm{C}_{5}\right)$ associated with the $\mathrm{C}_{1}-\mathrm{C}_{5}$, and $\mathrm{C}_{4}-\mathrm{C}_{5}$ single bonds, respectively with the values of the basin population $2.08 \overline{\mathrm{e}}$ and relative fluctuation 0.51 for each one; two disynaptic basins $\mathrm{V}\left(\mathrm{C}_{1}-\mathrm{C}_{2}\right)$, and $\mathrm{V}\left(\mathrm{C}_{3}-\mathrm{C}_{4}\right)$ associated with the $\mathrm{C}_{1}-\mathrm{C}_{2}$ and $\mathrm{C}_{3}-\mathrm{C}_{4}$ single bonds, respectively with the values of the basin population $1.99 \overline{\mathrm{e}}$ and relative fluctuation 0.52 for each one; two disynaptic basins $V\left(C_{2}-C_{3}\right)$ and $V^{\prime}\left(C_{2}-C_{3}\right)$ associated with the $C_{2}=C_{3}$ double bond, integrating to $3.47 \overline{\mathrm{e}}(1.77 \overline{\mathrm{e}}+1.70 \overline{\mathrm{e}})$, with the relative fluctuation 0.58 ; two disynaptic basins $\mathrm{V}\left(\mathrm{C}_{5}-\mathrm{O}\right)$ and $\mathrm{V}^{\prime}\left(\mathrm{C}_{5}-\mathrm{O}\right)$ associated with the $\mathrm{C}_{5}=\mathrm{O}$ double bond, integrating to $2.43 \overline{\mathrm{e}}(1.25 \overline{\mathrm{e}}+1.18 \overline{\mathrm{e}})$ with the relative fluctuation 0.71 ; and two monosynaptic basins $\mathrm{V}(\mathrm{O})$ and $\mathrm{V}^{\prime}(\mathrm{O})$ associated with the located lone pairs on the oxygen atom, integrating to $5.23 \mathrm{e}$ (2.68 $\overline{\mathrm{e}}+2.55 \overline{\mathrm{e}}$ ), with the relative fluctuation 0.44 for each one. The relative fluctuation values for carbon-carbon single bond and $\mathrm{C}_{5}=\mathrm{O}$ bond in $\mathbf{C P E}$ indicate that the electron density are localized and delocalized with respect to carbon-carbon bonds in benzene. The electron density for $\mathrm{C}_{2}=\mathrm{C}_{3}$ double bond is delocalized slightly smaller than the carbon-carbon bonds in benzene. The basin populations for $\mathrm{C}-\mathrm{C}$ single bonds are very close to the formal value of $2 \overline{\mathrm{e}}$, while basin populations of $\mathrm{C}_{2}=\mathrm{C}_{3}$ and $\mathrm{C}_{5}=\mathrm{O}$ double bonds are less than the formal value of $4 \overline{\mathrm{e}}$ in which the missed electrons are located on nonbonding $\mathrm{V}(\mathrm{O})$ and $\mathrm{V}^{\prime}(\mathrm{O})$ basins. Similar to $\mathbf{C H D}$, in the CPE the carbon-oxygen bond is highly polarized with a large weight of resonance hybrid 2 (see Scheme 2) and the GEDT equal to 0.10 e fluxes from BD fragment to the CO. The SSD I entails an energetic cost of $8.7 \mathrm{~kJ} \mathrm{~mol}^{-1}$ and connects to the second SSD with a cusp (C) type catastrophe. The SSD II, $1.512 \leq d \mathrm{C}_{1,4}-\mathrm{C}_{5}(\AA)<1.765$, takes place from $\mathbf{P}_{1}$ point at $\mathrm{Rx}=$ $-7.968 \mathrm{amu}^{1 / 2} \mathrm{Bohr}$ and ends before $\mathbf{P}_{2}$ point. In the first turning point, the valence disynaptic basins $\mathrm{V}\left(\mathrm{C}_{5}-\mathrm{O}\right)$ and $\mathrm{V}^{\prime}\left(\mathrm{C}_{5}-\mathrm{O}\right)$ are merged into a new disynaptic basin $\mathrm{V}\left(\mathrm{C}_{5}-\mathrm{O}\right)$ with the basin population of $2.45 \overline{\mathrm{e}}$, and, the GEDT has slightly decreased to $0.09 \overline{\mathrm{e}}$. This SSD is the most energetic step that entails an energetic cost of $135.3 \mathrm{~kJ} . \mathrm{mol}^{-1}$. 

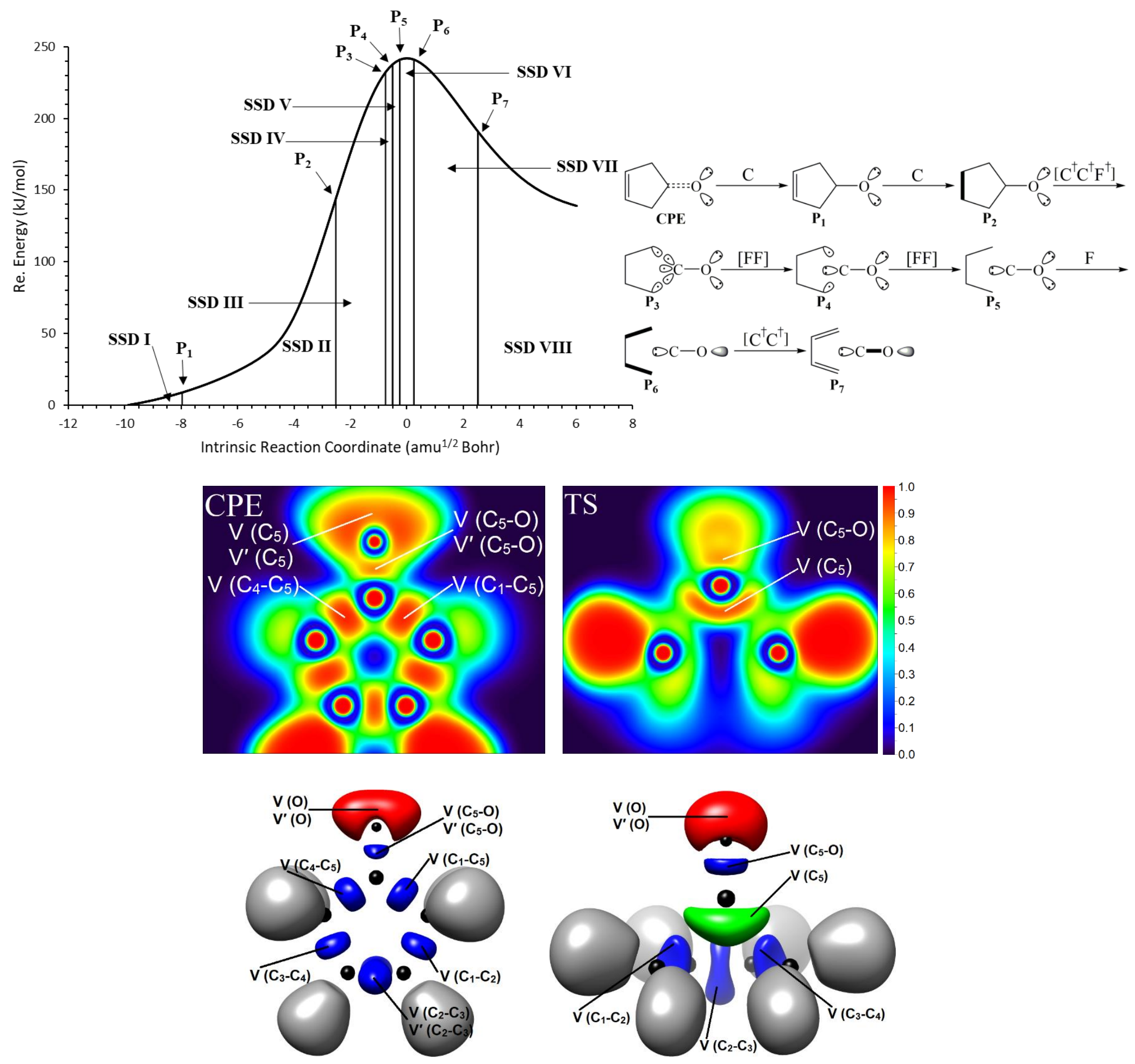

Figure 3. Top of the graph, energy profile for decarbonylation reaction of CPE with marked SSDs obtained from the ELF topological analysis; and Lewis type representation of the reaction mechanism (Bold bonds represent partial double bonds, filled ellipses indicate LPs monosynaptic basins with a population larger than $4.0 \overline{\mathrm{e}}$, and small ellipses with one dot indicate non-bonding pseudoradical centers). Below the graph, color-filled maps of the ELF (in the molecular plane defined by plane of the $\mathrm{C}_{1}-\mathrm{C}_{4}-\mathrm{C}_{5}$ ) and snapshots of the ELF localization domains $(\eta=0.8-0.81$; Color code: black for core basins, grey for protonated disynaptic basins, blue for disynaptic basins, red for LPs monosynaptic basins of $\mathrm{O}$ atom, and green for LPs monosynaptic basins of $\mathrm{C}$ atom) for reactant and TS. 
Table 2. Integrated ELF basin populations in different SSDs along the decarbonylation reaction of CPE calculated at the

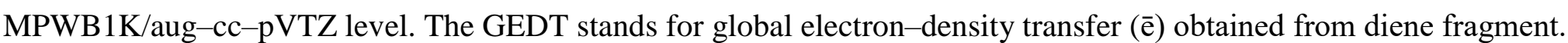

\begin{tabular}{|c|c|c|c|c|c|c|c|c|c|}
\hline \multirow{2}{*}{$\begin{array}{l}\text { SSD } \\
\text { Points }\end{array}$} & \multicolumn{2}{|c|}{ SSD I } & SSD II & SSD III & SSD IV & SSD V & SSD VI & \multicolumn{2}{|c|}{ SSD VII $\quad$ SSD VIII } \\
\hline & CPE & $\mathbf{P}_{1}$ & $\mathbf{P}_{2}$ & $\mathbf{P}_{3}$ & $\mathbf{P}_{4}$ & $\mathbf{P}_{5}$ & $\mathbf{P}_{6}$ & $\mathbf{P}_{7}$ & $\mathrm{BD}+\mathrm{CO}$ \\
\hline$d \mathrm{C}_{1}-\mathrm{C}_{5}(\AA)$ & 1.514 & 1.512 & 1.765 & 1.991 & 2.024 & 2.057 & 2.124 & 2.432 & - \\
\hline$d \mathrm{C}_{4}-\mathrm{C}_{5}(\AA)$ & 1.514 & 1.512 & 1.765 & 1.991 & 2.024 & 2.057 & 2.124 & 2.432 & - \\
\hline GEDT & 0.10 & 0.09 & 0.04 & 0.02 & 0.02 & 0.02 & 0.02 & 0.01 & - \\
\hline $\mathrm{V}\left(\mathrm{C}_{1}-\mathrm{C}_{2}\right)$ & 1.99 & 2.01 & 2.15 & 2.54 & 2.62 & 2.93 & 3.00 & 1.69 & 1.74 \\
\hline $\mathrm{V}^{\prime}\left(\mathrm{C}_{1}-\mathrm{C}_{2}\right)$ & - & - & - & - & - & - & - & 1.52 & 1.60 \\
\hline $\mathrm{V}\left(\mathrm{C}_{2}-\mathrm{C}_{3}\right)$ & 1.77 & 1.73 & 3.29 & 2.98 & 2.90 & 2.82 & 2.67 & 2.33 & 2.20 \\
\hline $\mathrm{V}^{\prime}\left(\mathrm{C}_{2}-\mathrm{C}_{3}\right)$ & 1.70 & 1.67 & - & - & - & - & - & - & - \\
\hline $\mathrm{V}\left(\mathrm{C}_{3}-\mathrm{C}_{4}\right)$ & 1.99 & 2.01 & 2.15 & 2.54 & 2.62 & 2.93 & 3.00 & 1.69 & 1.74 \\
\hline $\mathrm{V}^{\prime}\left(\mathrm{C}_{3}-\mathrm{C}_{4}\right)$ & - & - & - & - & - & - & - & 1.52 & 1.60 \\
\hline $\mathrm{V}\left(\mathrm{C}_{1}-\mathrm{C}_{5}\right)$ & 2.08 & 2.02 & 1.85 & - & - & - & - & - & - \\
\hline $\mathrm{V}\left(\mathrm{C}_{4}-\mathrm{C}_{5}\right)$ & 2.08 & 2.02 & 1.85 & - & - & - & - & - & - \\
\hline $\mathrm{V}\left(\mathrm{C}_{5}-\mathrm{O}\right)$ & 1.25 & 2.45 & 2.54 & 2.71 & 2.75 & 2.80 & 2.88 & 3.04 & 3.16 \\
\hline $\mathrm{V}^{\prime}\left(\mathrm{C}_{5}-\mathrm{O}\right)$ & 1.18 & - & - & - & - & - & - & - & - \\
\hline $\mathrm{V}(\mathrm{O})$ & 2.68 & 2.63 & 2.58 & 2.45 & 2.40 & 2.38 & 4.56 & 4.35 & 4.18 \\
\hline $\mathrm{V}^{\prime}(\mathrm{O})$ & 2.55 & 2.51 & 2.47 & 2.32 & 2.31 & 2.28 & - & - & - \\
\hline $\mathrm{V}\left(\mathrm{C}_{1}\right)$ & - & - & - & 0.22 & 0.28 & - & - & - & - \\
\hline $\mathrm{V}\left(\mathrm{C}_{4}\right)$ & - & - & - & 0.22 & 0.28 & - & - & - & - \\
\hline $\mathrm{V}\left(\mathrm{C}_{5}\right)$ & - & - & - & 0.18 & 2.47 & 2.48 & 2.48 & 2.48 & 2.49 \\
\hline $\mathrm{V}^{\prime}\left(\mathrm{C}_{5}\right)$ & - & - & - & 1.26 & - & - & - & - & - \\
\hline $\mathrm{V}^{\prime \prime}\left(\mathrm{C}_{5}\right)$ & - & - & - & 1.26 & - & - & - & - & - \\
\hline
\end{tabular}


The SSD III, $1.765 \leq d \mathrm{C}_{1,4}-\mathrm{C}_{5}(\AA)<1.991$, begins from $\mathbf{P}_{2}$ point at $\mathrm{Rx}=-2.517 \mathrm{amu}{ }^{1 / 2} \mathrm{Bohr}$ and finishes before $\mathbf{P}_{\mathbf{3}}$ point with an increment of $88.2 \mathrm{~kJ} . m o l^{-1}$ in energy. The second turning point is a cusp (C) type catastrophe which is identified in the region of $\mathrm{C}_{2}$ and $\mathrm{C}_{3}$ atoms. At the beginning of this $S S D$, the valence disynaptic basins $V\left(C_{2}-C_{3}\right)$ and $V^{\prime}\left(C_{2}-C_{3}\right)$ are merged into a new $\mathrm{V}\left(\mathrm{C}_{2}-\mathrm{C}_{3}\right)$ with a basin population of $3.29 \overline{\mathrm{e}}$, and GEDT decreased to $0.04 \mathrm{e}$. The SSD IV, $1.991 \leq d \mathrm{C}_{1,4}-\mathrm{C}_{5}(\AA)<2.024$, starts with the three concurrent cusp-cusp-fold $\left(\mathrm{C}^{\dagger} \mathrm{C}^{\dagger} \mathrm{F}^{\dagger}\right)$ type catastrophes from $\mathbf{P}_{\mathbf{3}}$ point at $\mathrm{Rx}=-0.755 \mathrm{amu}{ }^{1 / 2} \mathrm{Bohr}$ and ends before $\mathbf{P}_{\mathbf{4}}$ point. The new nonbonding monosynaptic basin $\mathrm{V}\left(\mathrm{C}_{5}\right)$ is created on $\mathrm{C}_{5}$ atom in the fold $\left(\mathrm{F}^{\dagger}\right)$ type catastrophe with a basin population of $0.18 \overline{\mathrm{e}}$. On the other hand, this turning point is related to the homolitic $\mathrm{C}_{1}-\mathrm{C}_{5}$ and $\mathrm{C}_{4}-\mathrm{C}_{5}$ bond breaking, and two concurrent cusp $\left(\mathrm{C}^{\dagger} \mathrm{C}^{\dagger}\right)$ type catastrophes lead to the formation of two monosynaptic basins $\mathrm{V}\left(\mathrm{C}_{1}\right)$ and $\mathrm{V}\left(\mathrm{C}_{4}\right)$ with a basin population of $0.22 \overline{\mathrm{e}}$ for each one which are associated to the pseudoradical centers on the $\mathrm{C}_{1}$ and $\mathrm{C}_{4}$ atoms, respectively; and two monosynaptic basins $\mathrm{V}^{\prime}\left(\mathrm{C}_{5}\right)$ and $\mathrm{V}^{\prime \prime}\left(\mathrm{C}_{5}\right)$ with a basin population of $1.26 \mathrm{e}$ for each one which are associated to the pseudoradical centers localized on $\mathrm{C}_{5}$ atom. At the starting point of this SSD, the valence disynaptic basins $\mathrm{V}\left(\mathrm{C}_{1}-\mathrm{C}_{2}\right)$ and $\mathrm{V}\left(\mathrm{C}_{3}-\mathrm{C}_{4}\right)$ are populated by $0.39 \overline{\mathrm{e}}$ each one, $\mathrm{V}\left(\mathrm{C}_{2}-\mathrm{C}_{3}\right)$ is depopulated by $0.31 \overline{\mathrm{e}}$; and GEDT marginally decreased to $0.02 \overline{\mathrm{e}}$.

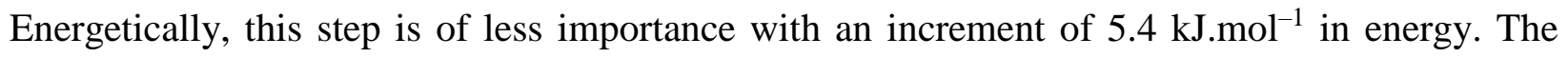
SSD $\mathbf{V}, 2.024 \leq d \mathrm{C}_{1,4}-\mathrm{C}_{5}(\AA)<2.057$, is determined by two concurrent fold (FF) type catastrophes started from $\mathbf{P}_{4}$ point at $\mathrm{Rx}=-0.503 \mathrm{amu}^{1 / 2} \mathrm{Bohr}$ and ended before $\mathbf{P}_{5}$ point that entails an energetic cost of $3.1 \mathrm{~kJ} \mathrm{~mol}^{-1}$. Three monosynaptic basins $\mathrm{V}\left(\mathrm{C}_{5}\right), \mathrm{V}^{\prime}\left(\mathrm{C}_{5}\right)$, and $\mathrm{V}^{\prime \prime}\left(\mathrm{C}_{5}\right)$ are merged into a new monosynaptic basin V $\left(\mathrm{C}_{5}\right)$ with a basin population of $2.47 \overline{\mathrm{e}}$. In this SSD the GEDT value remains at $0.02 \overline{\mathrm{e}}$ and this value will be unchanged up to $\mathbf{P}_{6}$ point. The SSD VI, $2.057 \leq d \mathrm{C}_{1,4}-\mathrm{C}_{5}(\AA)<2.124$, begins with two simultaneous fold (FF) type catastrophes from $\mathbf{P}_{5}$ point at $\mathrm{Rx}=-0.251 \mathrm{amu}^{1 / 2}$ Bohr and finishes before $\mathbf{P}_{6}$ point. This SSD is important because its ELF topology analysis characterizes the TS of the reaction. At the turning point two monosynaptic basins $\mathrm{V}\left(\mathrm{C}_{1}\right)$ and $\mathrm{V}\left(\mathrm{C}_{4}\right)$ are annihilated and their electrons are transferred to the disynaptic basins $\mathrm{V}\left(\mathrm{C}_{1}-\mathrm{C}_{2}\right)$ and $\mathrm{V}\left(\mathrm{C}_{3}-\mathrm{C}_{4}\right)$ with a basin population of $2.93 \overline{\mathrm{e}}$ for each one. The SSD VII, $2.124 \leq d \mathrm{C}_{1,4}-\mathrm{C}_{5}(\AA)<2.432$, is started from $\mathbf{P}_{6}$ point at $\mathrm{Rx}=-0.251 \mathrm{amu}^{1 / 2} \mathrm{Bohr}$ and finished before $\mathbf{P}_{7}$ point. In this SSD, monosynaptic basins $\mathrm{V}(\mathrm{O})$ and $\mathrm{V}^{\prime}(\mathrm{O})$ have been merged into a new monosynaptic basin $\mathrm{V}(\mathrm{O})$ with a basin population of $4.56 \mathrm{e}$ due to the fold $(\mathrm{F})$ type 
catastrophe. Finally, the last turning point is found at $\mathrm{Rx}=2.517 \mathrm{amu}^{1 / 2} \mathrm{Bohr}, 2.432 \leq d \mathrm{C}_{1,4}-\mathrm{C}_{5}$ $(\AA)$, in the region between the SSD VII and SSD VIII. Two concurrent cusp $\left(\mathrm{C}^{\dagger} \mathrm{C}^{\dagger}\right)$ type catastrophes result in splitting of disynaptic basins $\mathrm{V}\left(\mathrm{C}_{1}-\mathrm{C}_{2}\right)$ and $\mathrm{V}\left(\mathrm{C}_{3}-\mathrm{C}_{4}\right)$ into two disynaptic basins $\mathrm{V}\left(\mathrm{C}_{1}-\mathrm{C}_{2}\right), \mathrm{V}^{\prime}\left(\mathrm{C}_{1}-\mathrm{C}_{2}\right)$ and $\mathrm{V}\left(\mathrm{C}_{3}-\mathrm{C}_{4}\right), \mathrm{V}^{\prime}\left(\mathrm{C}_{3}-\mathrm{C}_{4}\right)$, with the basin populations $1.69 \overline{\mathrm{e}}$, $1.52 \mathrm{e}$ for each pairs, respectively. It is worth noting that the most electron redistribution at this turning point is related to the depopulation of disynaptic basin $\mathrm{V}\left(\mathrm{C}_{2}-\mathrm{C}_{3}\right)$ by $0.34 \overline{\mathrm{e}}$. The GEDT at the beginning of this SSD decreases to $0.01 \overline{\mathrm{e}}$. The electron redistribution continues until the BD and CO molecules are completely separated.

The ELF topological analysis of isolated BD molecule shows two pairs disynaptic basins V $\left(\mathrm{C}_{1}-\mathrm{C}_{2}\right), \mathrm{V}^{\prime}\left(\mathrm{C}_{1}-\mathrm{C}_{2}\right)$ and $\mathrm{V}\left(\mathrm{C}_{3}-\mathrm{C}_{4}\right), \mathrm{V}^{\prime}\left(\mathrm{C}_{3}-\mathrm{C}_{4}\right)$ associated with the $\mathrm{C}_{1}=\mathrm{C}_{2}$ and $\mathrm{C}_{3}=\mathrm{C}_{4}$ double bonds, respectively, integrating to $3.34 \overline{\mathrm{e}}(1.74 \overline{\mathrm{e}}+1.60 \overline{\mathrm{e}})$ with relative fluctuation 0.55 for each bond; and one disynaptic basin $\mathrm{V}\left(\mathrm{C}_{2}-\mathrm{C}_{3}\right)$ associated with the $\mathrm{C}_{2}-\mathrm{C}_{3}$ single bond with the values of the basin population $2.20 \overline{\mathrm{e}}$ and relative fluctuation 0.53 . During the reaction process $\mathrm{C}_{1}-\mathrm{C}_{2}$ and $\mathrm{C}_{3}-\mathrm{C}_{4}$ bonds have been populated by $1.35 \overline{\mathrm{e}}$ for each one while $\mathrm{C}_{2}-\mathrm{C}_{3}$ bond have been depopulated by $1.27 \overline{\mathrm{e}}$. The relative fluctuation values indicate that the carbon-carbon bonds are more localized in BD molecule respect to the carbon-carbon bonds in benzene ring.

The thermal decarbonylation of $\mathbf{B C H}$ can be represented by SSDs associated to the sequence of catastrophes BCH: $1-8-\mathrm{CC}\left[\mathrm{C}^{\dagger} \mathrm{C}^{\dagger}\right] \mathrm{F}[\mathrm{FF}] \mathrm{F}^{\mathrm{TS}}\left[\mathrm{C}^{\dagger} \mathrm{C}^{\dagger}\right]-0$ : $\mathbf{C D}+\mathrm{CO}$. The first SSD, $1.523 \leq d \mathrm{C}_{1}-\mathrm{C}_{7}$ $(\AA)<1.527$ and $1.523 \leq d \mathrm{C}_{1}-\mathrm{C}_{7}(\AA)<1.525$, begins where the ELF topology is similar to the BCH, with eleven valence bonding disynaptic and two monosynaptic basins. The ELF topology of $\mathbf{B C H}$ exhibits two disynaptic basins $\mathrm{V}\left(\mathrm{C}_{1}-\mathrm{C}_{2}\right)$, and $\mathrm{V}\left(\mathrm{C}_{3}-\mathrm{C}_{4}\right)$ associated with the $\mathrm{C}_{1}-\mathrm{C}_{2}$, and $\mathrm{C}_{3}-\mathrm{C}_{4}$ single bonds, respectively with the values of the basin population $2.02 \overline{\mathrm{e}}$ and relative fluctuation 0.54 for each one; two disynaptic basins $\mathrm{V}\left(\mathrm{C}_{1}-\mathrm{C}_{6}\right)$, and $\mathrm{V}\left(\mathrm{C}_{4}-\mathrm{C}_{5}\right)$ associated with the $\mathrm{C}_{1}-\mathrm{C}_{6}$ and $\mathrm{C}_{4}-\mathrm{C}_{5}$ single bonds, respectively with the values of the basin population $1.81 \overline{\mathrm{e}}$ and relative fluctuation 0.54 for each one; two disynaptic basins $\mathrm{V}\left(\mathrm{C}_{1}-\mathrm{C}_{7}\right)$, and $\mathrm{V}\left(\mathrm{C}_{4}-\mathrm{C}_{7}\right)$ associated with the $\mathrm{C}_{1}-\mathrm{C}_{7}$ and $\mathrm{C}_{4}-\mathrm{C}_{7}$ single bonds, respectively with the values of the basin population $2.03 \overline{\mathrm{e}}$ and relative fluctuation 0.52 for each one; two disynaptic basins $\mathrm{V}\left(\mathrm{C}_{2}-\mathrm{C}_{3}\right)$ and $\mathrm{V}^{\prime}\left(\mathrm{C}_{2}-\mathrm{C}_{3}\right)$ associated with the $\mathrm{C}_{2}=\mathrm{C}_{3}$ double bond, integrating to $3.40 \overline{\mathrm{e}}(1.72 \overline{\mathrm{e}}+1.68 \overline{\mathrm{e}})$, with the relative fluctuation 0.62 ; one disynaptic basin $\mathrm{V}\left(\mathrm{C}_{5}-\mathrm{C}_{6}\right)$ associated with the $\mathrm{C}_{5}-\mathrm{C}_{6}$ single bond, with the basin population of $1.87 \overline{\mathrm{e}}$ and relative fluctuation 0.53 ; two disynaptic basins $\mathrm{V}$ 
$\left(\mathrm{C}_{7}-\mathrm{O}\right)$ and $\mathrm{V}^{\prime}\left(\mathrm{C}_{7}-\mathrm{O}\right)$ associated with the $\mathrm{C}_{7}=\mathrm{O}$ double bond, integrating to $2.42 \overline{\mathrm{e}}(1.22 \overline{\mathrm{e}}+$ $1.20 \overline{\mathrm{e}}$ ), with the relative fluctuation 0.72 ; and two monosynaptic basins $\mathrm{V}(\mathrm{O})$ and $\mathrm{V}^{\prime}(\mathrm{O})$ associated with the located lone pairs on the oxygen atom, integrating to $5.26 \overline{\mathrm{e}}(2.70 \overline{\mathrm{e}}+2.56 \overline{\mathrm{e}})$, with the relative fluctuation 0.45 for each one. The relative fluctuation values indicate that except of $\mathrm{C}_{2}=\mathrm{C}_{3}$ and $\mathrm{C}_{7}=\mathrm{O}$ double bonds, electron density for others are more localized with respect to carbon-carbon bonds in benzene. The electron density for $\mathrm{C}_{2}=\mathrm{C}_{3}$ double bond is approximately delocalized similar to carbon-carbon bonds in benzene ring while for $\mathrm{C}_{7}=\mathrm{O}$ double bond is greatly delocalized. The population of $\mathrm{C}_{1}-\mathrm{C}_{2}, \mathrm{C}_{3}-\mathrm{C}_{4}, \mathrm{C}_{1}-\mathrm{C}_{7}$, and $\mathrm{C}_{4}-\mathrm{C}_{7}$ bonds are very close to the formal value of $2 \overline{\mathrm{e}}$, which can verify the nature of them as single bonds. However, the population of other single and double bonds are less than the formal values of $2 \overline{\mathrm{e}}$ and $4 \overline{\mathrm{e}}$, respectively. It very clear that the missed electron density in the electron-depleted double bonds are transferred to the nonbonding $\mathrm{V}(\mathrm{O})$ and $\mathrm{V}^{\prime}(\mathrm{O})$ basins in such a manner that their populations are $1.26 \overline{\mathrm{e}}$ more than the formal value of $2 \overline{\mathrm{e}}$ for lone pairs. Similar to $\mathbf{C H D}$ and $\mathbf{C P E}$ molecules, the carbon-oxygen bond in $\mathbf{B C H}$ is highly polarized with a large weight of resonance hybrid 2 (see Scheme 2) and the GEDT equal to 0.10 e taking place from CO to the CD fragment. The first SSD connects to the SSD II $\left(1.527 \leq d \mathrm{C}_{1}-\mathrm{C}_{7}(\AA)<1.715\right.$ and $1.525 \leq d$ $\left.\mathrm{C}_{4}-\mathrm{C}_{7}(\AA)<1.711\right)$ at $\mathrm{Rx}=-5.301 \mathrm{amu}^{1 / 2} \mathrm{Bohr}\left(\mathbf{P}_{1}\right.$ point $)$ with a cusp $(\mathrm{C})$ type catastrophe in the $\mathrm{C}_{7}=\mathrm{O}$ region. At the first turning point, two disynaptic basins $\mathrm{V}\left(\mathrm{C}_{7}-\mathrm{O}\right)$ and $\mathrm{V}^{\prime}\left(\mathrm{C}_{7}-\mathrm{O}\right)$ are merged into a new disynaptic basin $\mathrm{V}\left(\mathrm{C}_{7}-\mathrm{O}\right)$ with a basin population of $2.47 \overline{\mathrm{e}}$. This SSD comprises an energetic cost of $63.8 \mathrm{~kJ} \mathrm{~mol}^{-1}$ and the GEDT at the starting point of it is slightly decreased to $0.09 \overline{\mathrm{e}}$. The SSD III, $1.715 \leq d \mathrm{C}_{1}-\mathrm{C}_{7}(\AA)<1.979$ and $1.711 \leq d \mathrm{C}_{4}-\mathrm{C}_{7}(\AA)<1.975$, is determined by a cusp (C) type catastrophe that is started from $\mathbf{P}_{2}$ point at $\mathrm{Rx}=-2.850$ $\mathrm{amu}^{1 / 2}$ Bohr and ended before $\mathbf{P}_{\mathbf{3}}$ point. This SSD is the most energetic step with an energetic cost of $94.6 \mathrm{~kJ} \cdot \mathrm{mol}^{-1}$. At the beginning of this $\mathrm{SSD}$, two disynaptic basins $\mathrm{V}\left(\mathrm{C}_{2}-\mathrm{C}_{3}\right)$ and $\mathrm{V}^{\prime}\left(\mathrm{C}_{2}-\mathrm{C}_{3}\right)$ are merged into a new disynaptic basin $\mathrm{V}\left(\mathrm{C}_{2}-\mathrm{C}_{3}\right)$ with a basin population of $3.26 \overline{\mathrm{e}}$ and the GEDT decreases to $0.06 \overline{\text { e}}$. The SSD IV, $1.979 \leq d \mathrm{C}_{1}-\mathrm{C}_{7}(\AA)<2.014$ and $1.975 \leq d \mathrm{C}_{4}-\mathrm{C}_{7}(\AA)<$ 2.010, begins from $\mathbf{P}_{3}$ point at $\mathrm{Rx}=-0.777 \mathrm{amu}^{1 / 2}$ Bohr and ends before $\mathbf{P}_{4}$ point with an increment of $5.1 \mathrm{~kJ} \cdot \mathrm{mol}^{-1}$ in energy. 

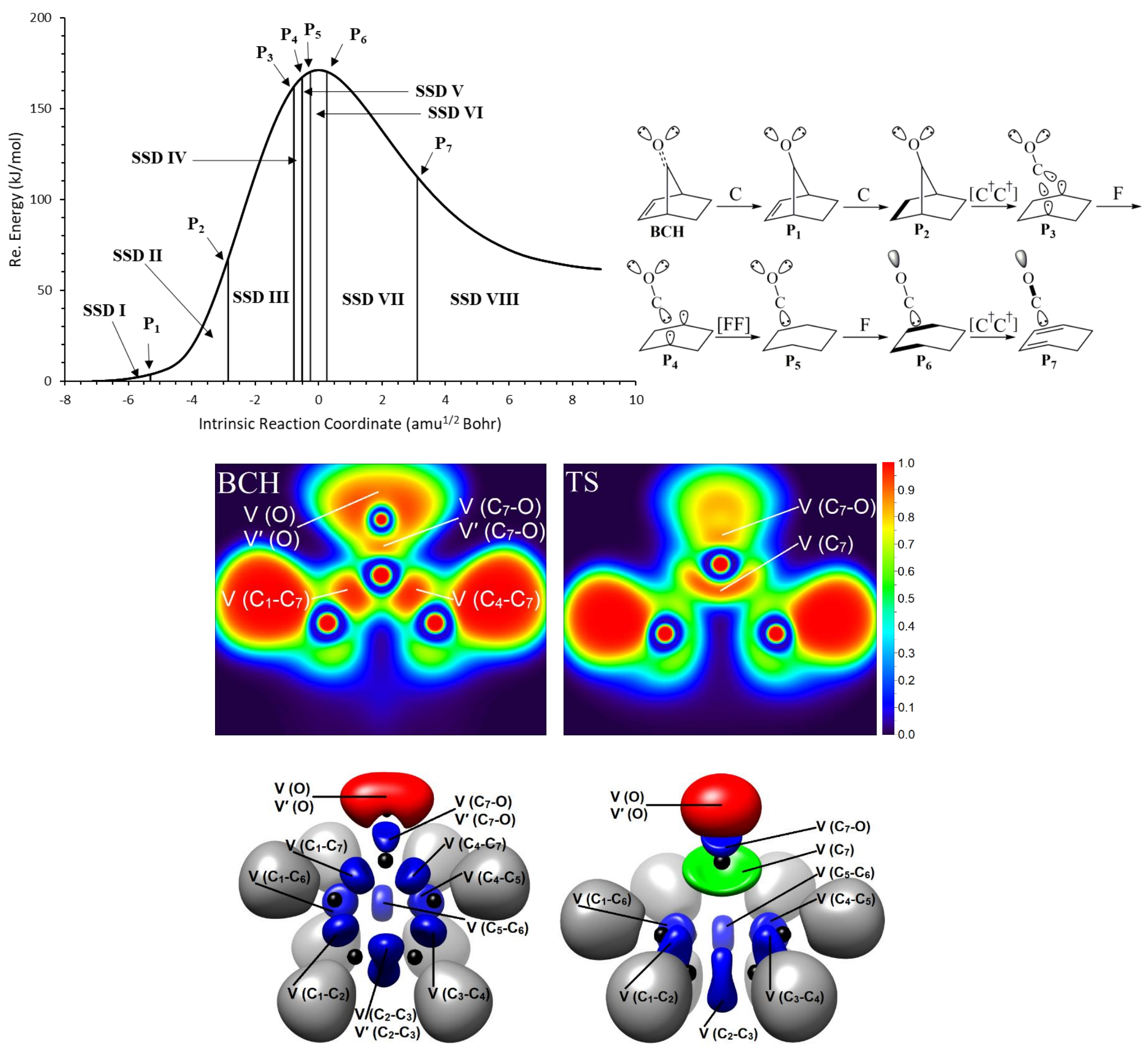

Figure 4. Top of the graph, energy profile for decarbonylation reaction of $\mathbf{B C H}$ with marked SSDs obtained from the ELF topological analysis; and Lewis type representation of the reaction mechanism (Bold bonds represent partial double bonds, filled ellipses indicate LPs monosynaptic basins with a population larger than $4.0 \overline{\mathrm{e}}$, and small ellipses with one dot indicate non-bonding pseudoradical centers). Below the graph, color-filled maps of the ELF (in the molecular plane defined by plane of the $\mathrm{C}_{1}-\mathrm{C}_{4}-\mathrm{C}_{7}$ ) and snapshots of the ELF localization domains $(\eta=0.8-0.81$; Color code: black for core basins, grey for protonated disynaptic basins, blue for disynaptic basins, red for LPs monosynaptic basins of $\mathrm{O}$ atom, and green for LPs monosynaptic basins of $\mathrm{C}$ atom) for reactant and TS. 
Table 3. Integrated ELF basin populations in different SSDs along the decarbonylation reaction of $\mathbf{B C H}$ calculated at the

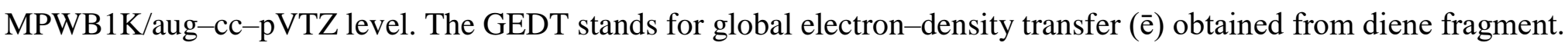

\begin{tabular}{|c|c|c|c|c|c|c|c|c|c|}
\hline \multirow{2}{*}{$\begin{array}{l}\text { SSD } \\
\text { Points }\end{array}$} & \multicolumn{2}{|c|}{ SSD I } & SSD II S & SSD III & SSD IV & SSD V & SSD VI & \multicolumn{2}{|c|}{ SSD VII $\quad$ SSD VIII } \\
\hline & BCH & $\mathbf{P}_{1}$ & $\mathbf{P}_{2}$ & $\mathbf{P}_{3}$ & $\mathbf{P}_{4}$ & $\mathbf{P}_{5}$ & $\mathbf{P}_{6}$ & $\mathbf{P}_{7}$ & $\mathrm{CD}+\mathrm{CO}$ \\
\hline$d \mathrm{C}_{1}-\mathrm{C}_{7}(\AA)$ & 1.523 & 1.527 & 1.715 & 1.979 & 2.014 & 2.048 & 2.118 & 2.504 & - \\
\hline$d \mathrm{C}_{4}-\mathrm{C}_{7}(\AA)$ & 1.523 & 1.525 & 1.711 & 1.975 & 2.010 & 2.044 & 2.113 & 2.501 & - \\
\hline GEDT & 0.10 & 0.09 & 0.06 & 0.03 & 0.03 & 0.03 & 0.03 & 0.02 & - \\
\hline $\mathrm{V}\left(\mathrm{C}_{1}-\mathrm{C}_{2}\right)$ & 2.02 & 2.03 & 2.16 & 2.55 & 2.65 & 2.96 & 3.03 & 1.75 & 1.72 \\
\hline $\mathrm{V}^{\prime}\left(\mathrm{C}_{1}-\mathrm{C}_{2}\right)$ & - & - & - & - & - & - & - & 1.52 & 1.64 \\
\hline $\mathrm{V}\left(\mathrm{C}_{2}-\mathrm{C}_{3}\right)$ & 1.72 & 1.71 & 3.26 & 2.95 & 2.87 & 2.79 & 2.64 & 2.29 & 2.23 \\
\hline $\mathrm{V}^{\prime}\left(\mathrm{C}_{2}-\mathrm{C}_{3}\right)$ & 1.68 & 1.66 & - & - & - & - & - & - & - \\
\hline $\mathrm{V}\left(\mathrm{C}_{3}-\mathrm{C}_{4}\right)$ & 2.02 & 2.02 & 2.16 & 2.55 & 2.65 & 2.96 & 3.03 & 1.75 & 1.72 \\
\hline $\mathrm{V}^{\prime}\left(\mathrm{C}_{3}-\mathrm{C}_{4}\right)$ & - & - & - & - & - & - & - & 1.52 & 1.64 \\
\hline $\mathrm{V}\left(\mathrm{C}_{4}-\mathrm{C}_{5}\right)$ & 1.81 & 1.82 & 1.90 & 1.98 & 2.00 & 2.00 & 2.02 & 2.03 & 2.05 \\
\hline $\mathrm{V}\left(\mathrm{C}_{5}-\mathrm{C}_{6}\right)$ & 1.87 & 1.87 & 1.87 & 1.86 & 1.86 & 1.86 & 1.86 & 1.87 & 1.88 \\
\hline$V\left(C_{1}-C_{6}\right)$ & 1.81 & 1.83 & 1.89 & 1.98 & 1.99 & 2.00 & 2.03 & 2.03 & 2.05 \\
\hline $\mathrm{V}\left(\mathrm{C}_{1}-\mathrm{C}_{7}\right)$ & 2.03 & 2.00 & 1.86 & - & - & - & - & - & - \\
\hline $\mathrm{V}\left(\mathrm{C}_{4}-\mathrm{C}_{7}\right)$ & 2.03 & 2.00 & 1.90 & - & - & - & - & - & - \\
\hline $\mathrm{V}\left(\mathrm{C}_{7}-\mathrm{O}\right)$ & 1.22 & 2.47 & 2.50 & 2.69 & 2.73 & 2.77 & 2.84 & 3.07 & 3.16 \\
\hline $\mathrm{V}^{\prime}\left(\mathrm{C}_{7}-\mathrm{O}\right)$ & 1.20 & - & - & - & - & - & - & - & - \\
\hline $\mathrm{V}(\mathrm{O})$ & 2.70 & 2.67 & 2.58 & 2.42 & 2.38 & 2.35 & 4.61 & 4.31 & 4.18 \\
\hline $\mathrm{V}^{\prime}(\mathrm{O})$ & 2.56 & 2.53 & 2.52 & 2.38 & 2.37 & 2.34 & - & - & - \\
\hline $\mathrm{V}\left(\mathrm{C}_{1}\right)$ & - & - & - & 0.33 & 0.28 & - & - & - & - \\
\hline $\mathrm{V}\left(\mathrm{C}_{4}\right)$ & - & - & - & 0.20 & 0.22 & - & - & - & - \\
\hline $\mathrm{V}\left(\mathrm{C}_{7}\right)$ & - & - & - & 1.29 & 2.54 & 2.50 & 2.50 & 2.49 & 2.49 \\
\hline $\mathrm{V}^{\prime}\left(\mathrm{C}_{7}\right)$ & - & - & - & 1.36 & - & - & - & - & - \\
\hline
\end{tabular}


At the beginning of this SSD, two $\mathrm{C}_{1}-\mathrm{C}_{7}$ and $\mathrm{C}_{4}-\mathrm{C}_{7}$ bonds are cleaved homolytically and two simultaneous cusp $\left(\mathrm{C}^{\dagger} \mathrm{C}^{\dagger}\right)$ type catastrophes lead to the transformation of disynaptic basin $\mathrm{V}$ $\left(\mathrm{C}_{1}-\mathrm{C}_{7}\right)$ into two monosynaptic basins $\mathrm{V}\left(\mathrm{C}_{1}\right)$ and $\mathrm{V}\left(\mathrm{C}_{7}\right)$ with the basin populations of $0.33 \overline{\mathrm{e}}$ and $1.29 \overline{\mathrm{e}}$, respectively, associated to the pseudoradical centers on the $\mathrm{C}_{1}$ and $\mathrm{C}_{7}$ atoms; and transformation of disynaptic basin $\mathrm{V}\left(\mathrm{C}_{4}-\mathrm{C}_{7}\right)$ into two monosynaptic basins $\mathrm{V}\left(\mathrm{C}_{4}\right)$ and $\mathrm{V}^{\prime}\left(\mathrm{C}_{7}\right)$ with the basin populations of $0.20 \overline{\mathrm{e}}$ and $1.36 \overline{\mathrm{e}}$, respectively, associated to the pseudoradical centers on the $\mathrm{C}_{4}$ and $\mathrm{C}_{7}$ atoms.

It should be noted that at the related turning point the disynaptic basins $V\left(C_{1}-C_{2}\right)$ and $V\left(C_{1}-C_{4}\right)$ are populated by $0.39 \overline{\mathrm{e}}$ for each one, while disynaptic basin $\mathrm{V}\left(\mathrm{C}_{2}-\mathrm{C}_{3}\right)$ is depopulated by $0.31 \overline{\mathrm{e}}$. At the $\mathbf{P}_{3}$ point the GEDT decreases to $0.03 \overline{\mathrm{e}}$ and this value is unchanged up to $\mathbf{P}_{6}$ point. The SSD V, $2.014 \leq d \mathrm{C}_{1}-\mathrm{C}_{7}(\AA)<2.048$ and $2.010 \leq d \mathrm{C}_{4}-\mathrm{C}_{7}(\AA)<2.044$, has been started with a fold (F) type catastrophe from $\mathbf{P}_{4}$ point at $\mathrm{Rx}=-0.518 \mathrm{amu}{ }^{1 / 2}$ Bohr and finished before $\mathbf{P}_{5}$ point with an energy cost of $2.9 \mathrm{~kJ} \mathrm{~mol}^{-1}$. In the related turning point, two monosynaptic basins $\mathrm{V}\left(\mathrm{C}_{7}\right)$ and $\mathrm{V}^{\prime}\left(\mathrm{C}_{7}\right)$ have been merged into a new monosynaptic basin $\mathrm{V}\left(\mathrm{C}_{7}\right)$ with a basin population of $2.54 \overline{\mathrm{e}}$, and its position is displaced from the bonding region. The SSD VI, $2.048 \leq d \mathrm{C}_{1}-\mathrm{C}_{7}(\AA)$ $<2.118$ and $2.044 \leq d \mathrm{C}_{4}-\mathrm{C}_{7}(\AA)<2.113$, is an important SSD because contains the TS of the reaction. This SSD starts with two concurrent fold (FF) type catastrophes from $\mathbf{P}_{5}$ point at $\mathrm{Rx}=$ $-0.259 \mathrm{amu}^{1 / 2}$ Bohr and ends before $\mathbf{P} 6$ point. In this SSD, two monosynaptic basins $\mathrm{V}\left(\mathrm{C}_{1}\right)$ and $\mathrm{V}$ $\left(\mathrm{C}_{4}\right)$ are disappeared and their electrons are transferred to the disynaptic basins $\mathrm{V}\left(\mathrm{C}_{1}-\mathrm{C}_{2}\right)$ and disynaptic basin $\mathrm{V}\left(\mathrm{C}_{3}-\mathrm{C}_{4}\right)$ with the basin population of 2.96 e for each one. The SSD VII, 2.118 $\leq d \mathrm{C}_{1}-\mathrm{C}_{7}(\AA)<2.504$ and $2.113 \leq d \mathrm{C}_{4}-\mathrm{C}_{7}(\AA)<2.501$, begins with a fold $(\mathrm{F})$ type catastrophe from $\mathbf{P}_{6}$ point at $\mathrm{Rx}=0.259 \mathrm{amu}{ }^{1 / 2}$ Bohr and ends before $\mathbf{P}_{7}$ point and results in merging of two monosynaptic basins $\mathrm{V}(\mathrm{O})$ and $\mathrm{V}^{\prime}(\mathrm{O})$ into a new monosynaptic basin $\mathrm{V}(\mathrm{O})$ with a basin population of $4.61 \overline{\mathrm{e}}$. The final turning point is observed in the region between the SSD VII and SSD VIII with two simultaneous cusp $\left(\mathrm{C}^{\dagger} \mathrm{C}^{\dagger}\right)$ type catastrophes at $\mathrm{Rx}=3.109 \mathrm{amu}^{1 / 2} \mathrm{Bohr}, 2.504$ $\leq d \mathrm{C}_{1}-\mathrm{C}_{7}(\AA)$ and $2.501 \leq d \mathrm{C}_{4}-\mathrm{C}_{7}(\AA)$. At the turning point, two disynaptic basins $\mathrm{V}\left(\mathrm{C}_{1}-\mathrm{C}_{2}\right)$ and $\mathrm{V}\left(\mathrm{C}_{3}-\mathrm{C}_{4}\right)$ have been split into two disynaptic basins $\mathrm{V}\left(\mathrm{C}_{1}-\mathrm{C}_{2}\right), \mathrm{V}^{\prime}\left(\mathrm{C}_{1}-\mathrm{C}_{2}\right)$ and $\mathrm{V}\left(\mathrm{C}_{3}-\mathrm{C}_{4}\right)$, $\mathrm{V}^{\prime}\left(\mathrm{C}_{3}-\mathrm{C}_{4}\right)$, with the basin populations $1.75 \overline{\mathrm{e}}, 1.52 \overline{\mathrm{e}}$ (integrating to $3.27 \overline{\mathrm{e}}$ ) for each pairs, respectively. Also, disynaptic basin $\mathrm{V}\left(\mathrm{C}_{2}-\mathrm{C}_{3}\right)$ and monosynaptic basin $\mathrm{V}(\mathrm{O})$ are depopulated 
by $0.35 \overline{\mathrm{e}}$ and $0.30 \overline{\mathrm{e}}$, respectively. The GEDT at the beginning of this SSD decreases to $0.02 \overline{\mathrm{e}}$, and electron redistribution continues until the $\mathbf{C D}$ and $\mathrm{CO}$ molecules are completely isolated.

The ELF topological feature of isolated $\mathbf{C D}$ molecule shows two disynaptic basins $\mathrm{V}\left(\mathrm{C}_{1}-\mathrm{C}_{6}\right)$, and $\mathrm{V}\left(\mathrm{C}_{4}-\mathrm{C}_{5}\right)$ associated with the $\mathrm{C}_{1}-\mathrm{C}_{6}$ and $\mathrm{C}_{4}-\mathrm{C}_{5}$ single bonds, respectively, with the values of basin population of $2.05 \overline{\mathrm{e}}$ and the relative fluctuation 0.52 for each one; two pairs disynaptic basins $\mathrm{V}\left(\mathrm{C}_{1}-\mathrm{C}_{2}\right), \mathrm{V}^{\prime}\left(\mathrm{C}_{1}-\mathrm{C}_{2}\right)$ and $\mathrm{V}\left(\mathrm{C}_{3}-\mathrm{C}_{4}\right), \mathrm{V}^{\prime}\left(\mathrm{C}_{3}-\mathrm{C}_{4}\right)$ associated with the $\mathrm{C}_{1}=\mathrm{C}_{2}$ and $\mathrm{C}_{3}=\mathrm{C}_{4}$ double bonds, respectively, integrating to $3.36 \overline{\mathrm{e}}(1.72 \overline{\mathrm{e}}+1.64 \overline{\mathrm{e}})$ with relative fluctuation 0.60 for each bonds; one disynaptic basin $\mathrm{V}\left(\mathrm{C}_{2}-\mathrm{C}_{3}\right)$ associated with the $\mathrm{C}_{2}-\mathrm{C}_{3}$ single bond with the values of the basin population $2.23 \overline{\mathrm{e}}$ and relative fluctuation 0.54 ; and one disynaptic basin $\mathrm{V}$ $\left(\mathrm{C}_{5}-\mathrm{C}_{6}\right)$ associated with the $\mathrm{C}_{5}-\mathrm{C}_{6}$ single bond with the values of the basin population $1.88 \overline{\mathrm{e}}$ and relative fluctuation 0.52 . During the reaction course $C_{1}-C_{2}, C_{3}-C_{4}, C_{1}-C_{2}$, and $C_{1}-C_{6}$ bonds are saturated by $1.34 \overline{\mathrm{e}}, 1.34 \overline{\mathrm{e}}, 0.24 \overline{\mathrm{e}}$, and $0.24 \overline{\mathrm{e}}$, respectively, $\mathrm{C}_{2}-\mathrm{C}_{3}$ bond is depopulated by $1.17 \overline{\mathrm{e}}$, and $\mathrm{C}_{5}-\mathrm{C}_{6}$ bond population is unchanged. The values of the relative fluctuation indicate that the delocalization degree of electron density for $\mathrm{C}_{1}=\mathrm{C}_{2}$ and $\mathrm{C}_{3}=\mathrm{C}_{4}$ double bonds are similar to carbon-carbon bonds in benzene ring, while other bonds are more localized.

The common product of the studied decarbonylations is carbon monoxide. For carbon monoxide, the ELF shows a disynaptic basin for carbon-oxygen bond with a basin population of $3.16 \overline{\mathrm{e}}$ and two lone pairs located on the oxygen and carbon atom with the basin population of $4.18 \overline{\mathrm{e}}$ and $2.49 \overline{\mathrm{e}}$, respectively.

In order to characterize the nature of interactions during the decarbonylation process, NCI analysis of the electron density has been carried out for reactants, transition states and turning points separating the SSDs along the reaction coordinates. The NCI analysis is related to the minima of $s(\rho)$ and the corresponding isosurfaces are constructed around these minima. The 2D NCI-plots (RDG versus electron density multiplied by $\lambda_{2}$ ) and the corresponding 3D NCI-plots (low-gradient isosurface) are displayed in Figure 5 and Figures S4-S6 (see supporting information). It is very clear that the non-covalent interactions can be observed when the bond breaking took place, in such a manner that NCI interaction critical point and ELF attractors are localized exactly at the same position. The 2D NCI-plot of CHD comprises two low-density low-gradient spikes at positive and negative values which are related to the orange and green colors in 3D NCI isosurface, corresponding to the steric repulsion due to ring closure and weak 
attractive $\mathrm{CH}-\mathrm{C}$ interactions, respectively. 2D NCI-plot of TS associated to the decarbonylation of CHD, shows two new low-density low-gradient spikes in the range of -0.06 to -0.08 which are revealed by bicolored (red-blue) ring-shaped isosurfaces. During the reaction course, spikes of 2D NCI-plot are shifted to -0.04 value and ring-shaped isosurfaces of TS evolve to a green-blue bicolored disk-shapes, corresponding to the attractive interaction. Bicolored isosurface is due to stabilizing interaction between triene and $\mathrm{CO}$ fragments revealed by the blue color, counterbalanced by destabilizing interactions from structural constraints, revealed by the red color.
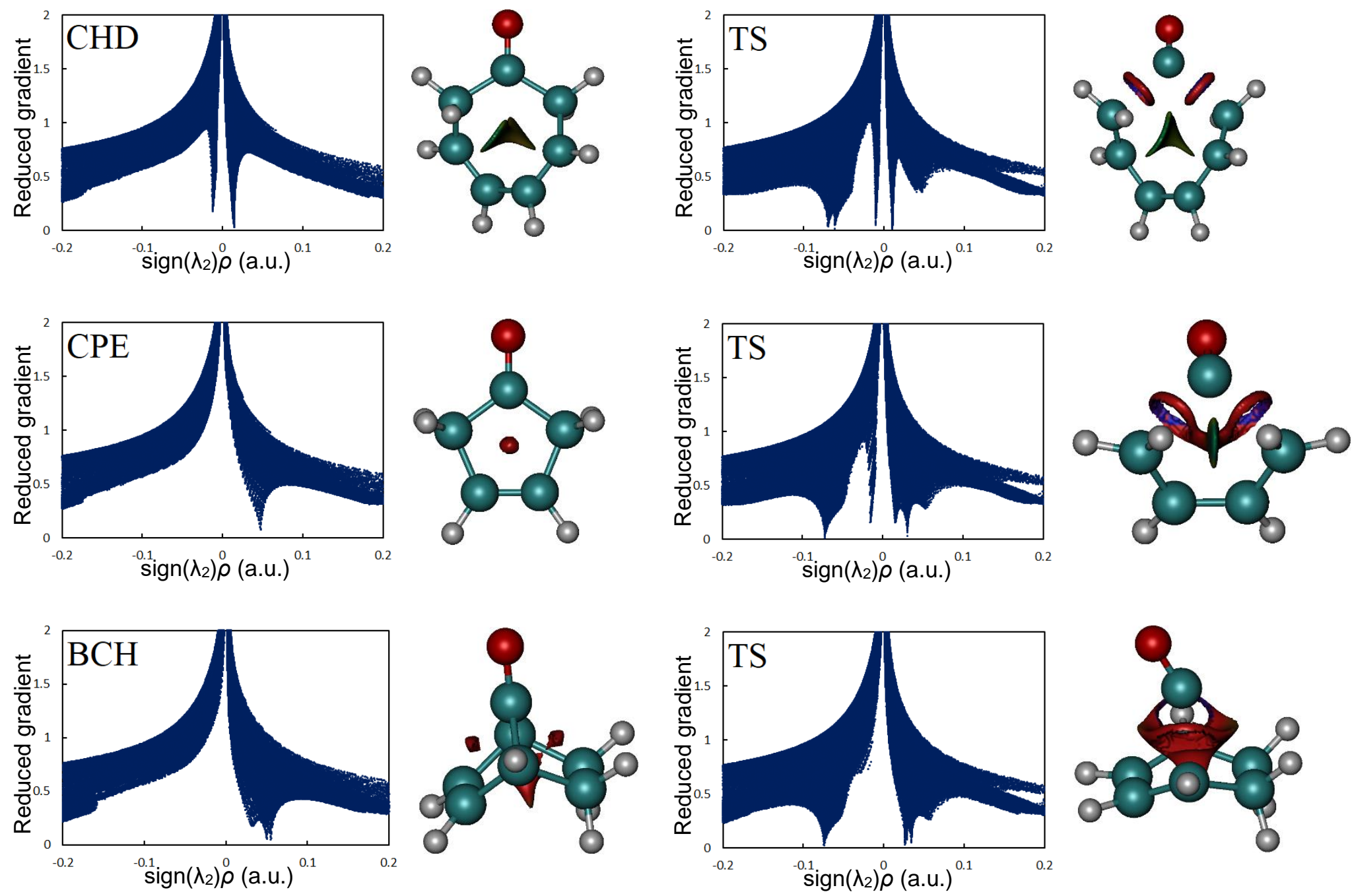

Figure 5. 2D NCI plots of the RDG, $s(\mathbf{r})$, versus the electron density multiplied by the sign of the second Hessian eigenvalue $\lambda_{2} \rho(\mathbf{r})$; and 3D NCI plots (isosurfaces) of the RDG, $s(\mathbf{r})$, correspond to $s=0.5$ a.u. and NCI color scale of $-0.03<\rho<0.03$ a.u. using SCF densities for reactants and transition states associated to the decarbonylation of $\mathbf{C H D}, \mathbf{C P E}$ and $\mathbf{B C H}$. 
2D NCI-plots of CPE and BCH show low-density low-gradient spike at positive values which are revealed by red color in their 3D NCI isosurfaces, corresponding to the ring closure. 2D NCI-plot of TS associated to the decarbonylation of CPE has two low-gradient spikes at negative values as a result of stabilizing interactions. The more negative spike is manifested by the green disk-shape isosurface and the other is displayed by bicolored (red-blue) ring-shaped isosurfaces. The green disk-shape isosurface is associated to the attractive interaction between two terminal $\mathrm{CH}_{2}$ groups. The bicolored ring-shaped isosurface is associated to the concurrent effects of stabilizing and destabilizing interactions which was discussed above. During the decarbonylation of CPE this isosurface evolves to a continuous green-blue bicolored isosurface associated with the attractive interactions. NCI plot analysis of TS associated to the decarbonylation of $\mathbf{B C H}$ is similar to CPE. During the decarbonylation of $\mathbf{B C H}$, the bicolored ring-shaped isosurface of TS evolves to a continuous orange-green-blue tricolored isosurface. The orange color of isosurface corresponds to the lack of bonding in the central area of CD molecule, while green and blue parts of isosurface are related to the attractive interactions between the diene fragment and $\mathrm{CO}$ molecule.

\section{Summary and Concluding Remarks}

In this contribution, bonding evolution theory (BET) coupled with non-covalent interaction (NCI) analysis have been used to disentangle the bond breaking/forming processes and electron redistribution along the reaction path associated with the cheletropic decarbonylation of unsaturated cyclic ketones cyclohepta-3,5-dien-1-one CHD, cyclopent-3-en-1-one CPE and bicyclo[2.2.1]hept-2-en-7-one BCH. All calculations have been carried out in the framework of density functional theory using hybrid functional MPWB1K in conjugation with aug-cc-pVTZ basis set. Cheletropic extrusion of CO from CHD, CPE and BCH can be classified as non-polar cyclo-elimination reactions with the theoretical activation energies (At 0

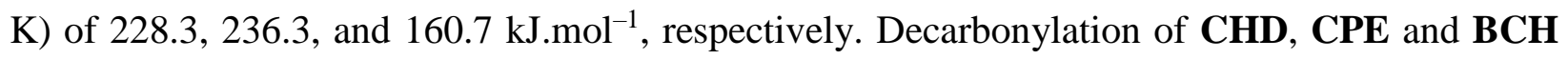
take place respectively along 11,8 , and 8 topologically differentiated successive structural stability domains and can be represented by the sequence of turning points as $\mathbf{C H D}$ : 1-11$\mathrm{C}[\mathrm{CC}] \mathrm{C}^{\dagger} \mathrm{C}^{\dagger} \mathrm{FFF}^{\mathrm{TS}} \mathrm{C}^{\dagger} \mathrm{C}^{\dagger} \mathrm{C}^{\dagger}-0: \mathbf{H T}+\mathrm{CO}, \mathbf{C P E}: 1-8-\mathrm{CC}\left[\mathrm{C}^{\dagger} \mathrm{C}^{\dagger} \mathrm{F}^{\dagger}\right][\mathrm{FF}][\mathrm{FF}] \mathrm{F}^{\mathrm{TS}}\left[\mathrm{C}^{\dagger} \mathrm{C}^{\dagger}\right]-0: \mathbf{B D}+\mathrm{CO}$, and $\mathbf{B C H}: 1-8-\mathrm{CC}\left[\mathrm{C}^{\dagger} \mathrm{C}^{\dagger}\right] \mathrm{F}[\mathrm{FF}] \mathrm{F}^{\mathrm{TS}}\left[\mathrm{C}^{\dagger} \mathrm{C}^{\dagger}\right]-0$ : $\mathbf{C D}+\mathrm{CO}$. Topological analysis of electron localization function (ELF) reveals that the decarbonylation of CHD, CPE and $\mathrm{BCH}$ can be 
described by i) depopulation of $\mathrm{C}=\mathrm{C}$ double bonds in diene/triene fragment, ii) $\mathrm{C}-\mathrm{C}$ bond breaking between the terminal carbon atoms of diene/triene and carbon atom of $\mathrm{CO}$ fragments at distance of $c a$. 1.9-2.0 $\AA$ accompanied by appearance of pseudoradical centers on terminal carbon atoms of diene/triene and increasing of monosynaptic basins on carbon atom of $\mathrm{CO}$, iii) disappearing of pseudoradical centers in the vicinity of the transition structure where the transition state is not reached yet, iv) redistribution and reduction in the number of nonbonding basins, and finally v) population of $\mathrm{C}-\mathrm{C}$ single bonds in the diene/triene framework. NCI analysis shows that the non-covalent interactions between two fragments are appeared when the bond breaking is started where the ELF attractors are localized. The corresponding isosurfaces are evolved to the typical attractive interaction (green and blue isosurfaces) during the reaction course.

\section{Supporting Information}

Additional figures concerning the ELF color-filled maps and NCI plots for reactants and turning points separating the SSDs along the decarbonylation of CHD, CPE and BCH. This material is available free of charge via the Internet at http://pubs.acs.org.

\section{Notes:}

The authors declare that there is no conflict of interest.

\section{References}

1. Berski, S.; Sensato, F. R.; Polo, V.; Andrés, J.; Safont, V. S. Olefin epoxidation by molybdenum peroxo compound: Molecular mechanism characterized by the electron localization function and catastrophe theory. J. Phys. Chem. A 2011, 115, 514-522.

2. Andrés, J.; Berski, S.; Contreras-García, J.; González-Navarrete, P. Following the molecular mechanism for the $\mathrm{NH}_{3}+\mathrm{LiH} \rightarrow \mathrm{LiNH}_{2}+\mathrm{H}_{2}$ chemical reaction: A study based on the joint use of the quantum theory of atoms in molecules (QTAIM) and noncovalent interaction (NCI) index. J. Phys. Chem. A 2014, 118, 1663-1672.

3. Polo, V.; Gonzalez-Navarrete, P.; Silvi, B.; Andres, J. An electron localization function and catastrophe theory analysis on the molecular mechanism of gas-phase identity SN2 reactions. Theor. Chem. Acc. 2008, 120, 341-349. 
4. Hohenberg, P.; Kohn, W. Inhomogeneous electron gas. Phys. Rev. B 1964, 136, 864-871.

5. Chauvin, R.; Lepetit, C.; Silvi, B.; Alikhani, E. Applications of Topological Methods in Molecular Chemistry. Springer International Publishing: Switzerland, 2016; Vol. 22.

6. Becke, A. D.; Edgecombe, K. E. A simple measure of electron localization in atomic and molecular systems. J. Chem. Phys. 1990, 92, 5397-5403.

7. Savin, A.; Silvi, B.; Colonna, F. Topological analysis of the electron localization function applied to delocalized bonds. Can. J. Chem. 1996, 74, 1088-1096.

8. Savin, A.; Silvi, B. Classification of chemical bonds based on topological analysis of electron localization functions. Nature 1994, 371, 683-686.

9. Savin, A.; Nesper, R.; Wengert, S.; Fässler, T. E. ELF: The Electron Localization Function. Angew. Chem. Int. Ed. Engl. 1997, 36, 1808-1832.

10. Polo, V.; Andres, J.; Castillo, R.; Berski, S.; Silvi, B. Understanding the molecular mechanism of the 1,3-dipolar cycloaddition between fulminic acid and acetylene in terms of the electron localization function and catastrophe theory. Chem. Eur. J. 2004, 10, 5165-5172.

11. Thom, R. Stabilité Structurelle et Morphogenèse. $2^{\text {nd }}$ ed.; Paris, 1977.

12. Andrés, J.; Berski, S.; Silvi, B. Curly arrows meet electron density transfers in chemical reaction mechanisms: from electron localization function (ELF) analysis to valenceshell electron-pair repulsion (VSEPR) inspired interpretation. Chem. Comm. 2016, 52, 81838195.

13. Krokidis, X.; Noury, S.; Silvi, B. Characterization of elementary chemical processes by catastrophe theory. J. Phys. Chem. A 1997, 101, 7277-7282.

14. Berski, S.; Andrés, J.; Silvi, B.; Domingo, L. R. New findings on the Diels-Alder reactions. An analysis based on the bonding evolution theory. J. Phys. Chem. A 2006, $110,13939-13947$.

15. Domingo, L. R. State of the art of the bonding changes along the Diels-Alder reaction between butadiene and ethylene: Refuting the pericyclic mechanism. Organic Chem. Curr. Res. 2013, 2, 120.

16. Domingo, L. R. Why Diels-Alder reactions are non-concerted processes? J. Chil. Chem. Soc. 2014, 59, 2615-2618. 
17. Domingo, L. R. A new $\mathrm{C}-\mathrm{C}$ bond formation model based on the quantum chemical topology of electron density. RSC Adv. 2014, 4, 32415-32428.

18. Domingo, L. R.; Aurell, M. J.; Pérez, P. The mechanism of ionic Diels-Alder reactions. A DFT study of the oxa-Povarov reaction. RSC Adv. 2014, 4, 16567-16577.

19. Domingo, L. R.; Aurell, M. J.; Sáez, J. A.; Mekelleche, S. M. Understanding the mechanism of the Povarov reaction. A DFT study. RSC Adv. 2014, 4, 25268-25278.

20. Domingo, L. R.; Chamorro, E.; Pérez, P. Understanding the mechanism of non-polar Diels-Alder reactions. A comparative ELF analysis of concerted and stepwise diradical mechanisms. Org. Biomol. Chem. 2010, 8, 5495-5504

21. Domingo, L. R.; Pérez, P. A quantum chemical topological analysis of the $\mathrm{C}-\mathrm{C}$ bond formation in organic reactions involving cationic species. Phys. Chem. Chem. Phys. 2014, 16, 14108-14115.

22. Domingo, L. R.; Pérez, P.; Sáez, J. A. Origin of the synchronicity in bond formation in polar Diels-Alder reactions: an ELF analysis of the reaction between cyclopentadiene and tetracyanoethylene. Org. Biomol. Chem. 2012, 10, 3841-3851.

23. Domingo, L. R.; Pérez, P.; Sáez, J. A. Understanding the regioselectivity in hetero DielsAlder reactions. An ELF analysis of the reaction between nitrosoethylene and 1vinylpyrrolidine. Tetrahedron 2013, 69, 107-114.

24. Polo, V.; Andrés, J.; Berski, S.; Domingo, L. R.; Silvi, B. Understanding reaction mechanisms in organic chemistry from catastrophe theory applied to the electron localization function topology. J. Phys. Chem. A 2008, 112, 7128-7136.

25. González-Navarrete, P.; Domingo, L. R.; Andrés, J.; Berski, S.; Silvi, B. Electronic fluxes during diels-alder reactions involving 1,2-benzoquinones: mechanistic insights from the analysis of electron localization function and catastrophe theory. J. Comput. Chem. 2012, 33, 2400-2411.

26. Berski, S.; Andrés, J.; Silvi, B.; Domingo, L. R. The joint use of catastrophe theory and electron localization function to characterize molecular mechanisms. A density functional study of the Diels-Alder reaction between ethylene and 1,3-butadiene. J. Phys. Chem. A 2003, 107, 6014-6024. 
27. Santos, J. C.; Andres, J.; Aizman, A.; Fuentealba, P.; Polo, V. A theoretical study on the reaction mechanism for the Bergman cyclization from the perspective of the electron localization function and catastrophe theory. J. Phys. Chem. A 2005, 109, 3687-3693.

28. Andres, J.; Berski, S.; Domingo, L. R.; Gonzalez-Navarrete, P. Nature of the ring-closure process along the rearrangement of octa-1,3,5,7-tetraene to cycloocta-1,3,5-triene from the perspective of the electron localization function and catastrophe theory. J. Comput. Chem. 2012, 33, 748-756.

29. Polo, V.; Andres, J. Lewis acid and substituent effects on the molecular mechanism for the nazarov reaction of penta-1,4-dien-3-one and derivatives. A topological analysis based on the combined use of electron localization function and catastrophe theory. $J$. Chem. Theory Comput. 2007, 3, 816-823.

30. Polo, V.; Andrés, J. A joint study based on the electron localization function and catastrophe theory of the chameleonic and centauric models for the Cope rearrangement of 1,5-hexadiene and its cyano derivatives. J. Comput. Chem. 2005, 26, 1427-1437.

31. Berski, S.; Durlak, P. The mechanism of Claisen rearrangement of allyl phenyl ether from the perspective of topological analysis of the ELF. New J.Chem. 2016, 40, 87178726.

32. González-Navarrete, P.; Andrés, J.; Berski, S. How a quantum chemical topology analysis enables prediction of electron density transfers in chemical reactions. The degenerated cope rearrangement of semibullvalene. J. Phys. Chem. Lett. 2012, 3, 25002505.

33. Domingo, L. R.; Pérez, P.; Sáez, J. A. Understanding C-C bond formation in polar reactions. An ELF analysis of the Friedel-Crafts reaction between indoles and nitroolefins. RSC Adv. 2013, 3, 7520-7528.

34. Domingo, L. R.; Ríos-Gutiérrez, M.; Sáez, J. A. Unravelling the mechanism of the ketene-imine Staudinger reaction. An ELF quantum topological analysis. RSC Adv. 2015, 5, 37119-37129.

35. Domingo, L. R.; Sáez, J. A. Understanding the selectivity in the formation of $\delta$-lactams vs. $\beta$-lactams in the Staudinger reactions of chloro-cyan-ketene with unsaturated imines. A DFT study. RSC Adv. 2014, 4, 58559-58566. 
36. Domingo, L. R.; Aurell, M. J.; Pérez, P. Understanding the polar mechanism of the ene reaction. A DFT study. Org. Biomol. Chem. 2014, 12, 7581-7590.

37. Pérez, P.; Domingo, L. R. A DFT study of inter- and intramolecular aryne ene reactions. Eur. J. Org. Chem. 2015, 2015, 2826-2834.

38. Polo, V.; Domingo, L. R.; Andrés, J. Better understanding of the ring-cleavage process of cyanocyclopropyl anionic derivatives. A theoretical study based on the electron localization function. J. Org. Chem. 2006, 71, 754-762.

39. Andrés, J.; Berski, S.; Domingo, L. R.; Polo, V.; Silvi, B. Describing the molecular mechanism of organic reactions by using topological analysis of electronic localization function. Curr. Org. Chem. 2011, 15, 3566-3575.

40. Santos, J. C.; Polo, V.; Andrés, J. An electron localization function study of the trimerization of acetylene: Reaction mechanism and development of aromaticity. Chem. Phys. Lett. 2005, 406, 393-397.

41. Benchouk, W.; Mekelleche, S. M.; Aurell, M. J.; Domingo, L. R. Understanding the regio- and chemoselective polar [3+2] cycloaddition of the Padwa carbonyl ylides with $\alpha$ methylene ketones. A DFT study. Tetrahedron 2009, 65, 4644-4651.

42. Domingo, L. R.; Ríos-Gutiérrez, M.; Pérez, P. A new model for C-C bond formation processes derived from the Molecular Electron-Density Theory in the study of the mechanism of [3+2] cycloaddition reactions of carbenoid nitrile ylides with electrondeficient ethylenes. Tetrahedron 2016, 72, 1524-1532.

43. Ríos-Gutiérrez, M.; Pérez, P.; Domingo, L. R. A bonding evolution theory study of the mechanism of [3+2] cycloaddition reactions of nitrones with electron-deficient ethylenes. RSC Adv. 2015, 5, 58464-58477.

44. Nacereddine, A. K.; Sobhi, C.; Djerourou, A.; Ríos-Gutiérrez, M.; Domingo, L. R. Nonclassical $\mathrm{CH} / \mathrm{O}$ hydrogen-bond determining the regio- and stereoselectivity in the $[3+2]$ cycloaddition reaction of (Z)-C-phenyl-Nmethylnitrone with dimethyl 2benzylidenecyclopropane-1,1-dicarboxylate. A topological electron-density study. $R S C$ $A d v$. 2015, 5, 99299-99311.

45. Domingo, L. R.; Ríos-Gutiérrez, M.; Chamorro, E.; Pérez, P. Electrophilic activation of $\mathrm{CO}_{2}$ in cycloaddition reactions towards a nucleophilic carbenoid intermediate: new 
defying insights from the molecular electron density theory. Theor. Chem. Acc. 2017, $136,1$.

46. Domingo, L. R.; Ríos-Gutiérrez, M.; Pérez, P. An MEDT study of the carbenoid-type [3 $+2]$ cycloaddition reactions of nitrile ylides with electron-deficient chiral oxazolidinones. Org. Biomol. Chem. 2016, 14, 10427-10436.

47. Ríos-Gutiérrez, M.; Chafaa, F.; Nacereddine, A. K.; Djerourou, A.; Domingo, L. R. A DFT study of [3+2] cycloaddition reactions of an azomethine iminewith $\mathrm{N}$-vinyl pyrrole and N-vinyl tetrahydroindole. J. Mol. Graph. Model. 2016, 70, 296-304.

48. Ríos-Gutiérrez, M.; Darù, A.; Tejero, T.; Domingo, L. R.; Merino, P. A molecular electron density theory study of the $[3+2]$ cycloaddition reaction of nitrones with ketenes. Org. Biomol. Chem. 2017, 15, 1618-1627.

49. Domingo, L. R.; Ríos-Gutiérrez, M.; Pérez, P. A DFT study of the ionic [2+2] cycloaddition reactions of keteniminium cations with terminal acetylenes. Tetrahedron 2015, 71, 2421-2427.

50. Domingo, L. R.; Ríos-Gutiérrez, M.; Pérez, P.; Chamorro, E. Understanding the [2n+2n] reaction mechanism between a carbenoid intermediate and $\mathrm{CO}_{2}$. Mol. Phys. 2016, 114, 1374-1391.

51. Zahedi, E.; Mozaffari, M.; Yousefi, L.; Shiroudi, A.; Deleuze, M. S. Kinetic and mechanistic study on the pyrolysis of 1,3-dihydroisothianaphthene-2,2-dioxide toward benzocyclobutene using RRKM and BET theories. Chem. Phys. 2017, 483-484, 12-25.

52. Zahedi, E.; Mozaffari, M.; Shahsavar, F.; Shiroudi, A.; Deleuze, M. S. Understanding the kinetics and mechanism of thermal cheletropic elimination of $\mathrm{N}_{2}$ from (2,5-dihydro1Hpyrrol-1-ium-1-ylidene) amide using RRKM and ELF theories. Res. Chem. Intermed. 2017, 43, 1575-1590.

53. Birney, D. M.; Ham, S.; Unruh, G. R. Pericyclic and pseudopericyclic thermal cheletropic decarbonylations: When can a pericyclic reaction have a planar, pseudopericyclic transition state? J. Am. Chem. Soc. 1997, 119, 4509-4517.

54. Rodríguez-Otero, J.; Cabaleiro-Lago, E. M.; Hermida-Ramón, J. M.; Peña-Gallego, A. DFT study of pericyclic and pseudopericyclic thermal cheletropic decarbonylations. Evaluation of magnetic properties. J. Org. Chem. 2003, 68, 8823-8830. 
55. Johnson, E. R.; Keinan, S.; Mori-Sánchez, P.; Contreras-García, J.; Cohen, A. J.; Yang, W. Revealing noncovalent interactions. J. Am. Chem. Soc. 2010, 132, 6498-6506.

56. Gillet, N.; Chaudret, R.; Contreras-García, J.; Yang, W.; Silvi, B.; Piquemal, J. P. Coupling quantum interpretative techniques: another look at chemical mechanisms in organic reactions. J. Chem. Theory Comput. 2012, 8, 3993-3997.

57. Frisch, M. J.; Trucks, G. W.; Schlegel, H. B.; Scuseria, G. E.; Robb, M. A.; Cheeseman, J. R.; Scalmani, G.; Barone, V.; Mennucci, B.; Petersson, G. A., et al. Gaussian, Inc., Wallingford CT, Gaussian 09, Revision D.01, 2013.

58. Zhao, Y.; Truhlar, D. G. Hybrid meta density functional theory methods for thermochemistry, thermochemical kinetics, and noncovalent interactions: The MPW1B95 and MPWB1K models and comparative assessments for hydrogen bonding and van der Waals interactions. J. Phys. Chem. A 2004, 108, 6908-6918.

59. Dunning-Jr., T. H. Gaussian basis sets for use in correlated molecular calculations. I. The atoms boron through neon and hydrogen. J. Chem. Phys. 1989, 90, 1007-1023.

60. Domingo, L. R. Molecular electron density theory: A modern view of reactivity in organic chemistry. Molecules 2016, 21, 1319.

61. Density Functionals from the Truhlar Group, https://comp.chem.umn.edu/info/dft.htm.

62. Li, X.; Frisch, M. J. Energy-represented direct inversion in the iterative subspace within a hybrid geometry optimization method. J. Chem. Theory Comput. 2006, 2, 835-839.

63. Hratchian, H. P.; Schlegel, H. B. Accurate reaction paths using a Hessian based predictor corrector integrator. J. Chem. Phys. 2004, 120, 9918-9924.

64. Hirshfeld, F. L. Bonded-atom fragments for describing molecular charge densities. Theor. Chem. Acc. 1977, 44, 129-138.

65. Noury, S.; Krokidis, X.; Fuster, F.; Silvi, B. TopMod package, 1997.

66. Lu, T.; Chen, F. Multiwfn: A multifunctional wavefunction analyzer. J. Comput. Chem. 2012, 33, 580-592.

67. Grin, Y.; Savin, A.; Silvi, B. The ELF Perspective of chemical bonding. In The Chemical Bond : Fundamental Aspects of Chemical Bonding, $1^{\text {st }}$ ed.; G. Frenking and S. Shaik, Eds. Wiley-VCH Verlag GmbH \& Co. KGaA.: USA, 2014. 
68. Contreras-García, J.; Johnson, E. R.; Keinan, S.; Chaudret, R.; Piquemal, J. P.; Beratan, D. N.; Yang, W. NCIPLOT: A program for plotting noncovalent interaction regions. $J$. Chem. Theory Comput. 2011, 7, 625-632.

69. Chaudret, R.; Courcy, B. d.; Contreras-García, J.; Gloaguen, E.; Zehnacker-Rentien, A.; Mons, M.; Piquemal, J.-P. Unraveling non-covalent interactions within flexible biomolecules: from electron density topology to gas phase spectroscopy. Phys. Chem. Chem. Phys. 2014, 16, 9876-9891.

70. Buxton, J. P.; Simpson, C. J. S. M. Thermal decarbonylations of unsaturated cyclic ketones: Kinetics and dynamics. Chem. Phys. 1986, 105, 307-316. 